\title{
Recent advances in enhancing the sensitivity of electrophoresis and electrochromatography in capillaries and microchips (2014 - 2016)
}

Michael C Breadmore ${ }^{1,8,9}$, Alain Wuethrich ${ }^{1}$, Feng $\mathrm{Li}^{1}$, Sui Ching Phung ${ }^{1}$, Umme Kalsoom $^{1}$, Joan M. Cabot $^{1,8}$, Masoomeh Tehrani Rokh ${ }^{9}$, Aliaa I Shallan ${ }^{7}$, Aemi S. Abdul Keyon ${ }^{2}$, Hong Heng See ${ }^{2,5}$, Mohamed Dawod ${ }^{6}$, Joselito P Quirino ${ }^{1}$.

1 Australian Centre of Research on Separation Science, School of Physical Science, University of Tasmania, Private Bag 75, Hobart, TAS 7001, Australia

2 Department of Chemistry, Faculty of Science, Universiti Teknologi Malaysia, 81310, UTM Johor Bahru, Johor, Malaysia

3 Department of Pharmaceutical Chemistry, Faculty of Pharmacy, Mahidol University, 447 SriAyudhaya Rd., Rajathevee, Bangkok 10400, Thailand

4 Australian Centre of Research on Separation Science, School of Pharmacy, Faculty of Health Sciences, University of Tasmania, Private Bag 26, Hobart, TAS 7001, Australia

5 Centre for Sustainable Nanomaterials, Ibnu Sina Institute for Scientific and industrial Research, Universiti Teknologi Malaysia, 81310 UTM Johor Bahru, Johor, Malaysia.

6 Department of Chemistry, University of Michigan, Ann Arbor, Michigan 48109, United States

7 Department of Analytical Chemistry, Faculty of Pharmacy, Helwan University, Cairo, Egypt

8 ARC Centre of Excellence for Electromaterials Science, School of Physical Science, University of Tasmania, Private Bag 75, Hobart, TAS 7001, Australia

9 ASTech, ARC Training Centre for Portable Analytical Separation Technologies, School of Physical Science, University of Tasmania, Private Bag 75, Hobart, TAS 7001, Australia

*Address Correspondence to:

Professor Michael Breadmore,

Australian Centre for Research on Separation Science,

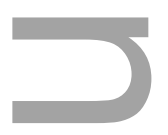

This is the author manuscript accepted for publication and has undergone full peer review but has not been through the copyediting, typesetting, pagination and proofreading process, which may lead to differences between this version and the Version of Record. Please cite this article as doi: 10.1002/elps.201600331.

This article is protected by copyright. All rights reserved. 


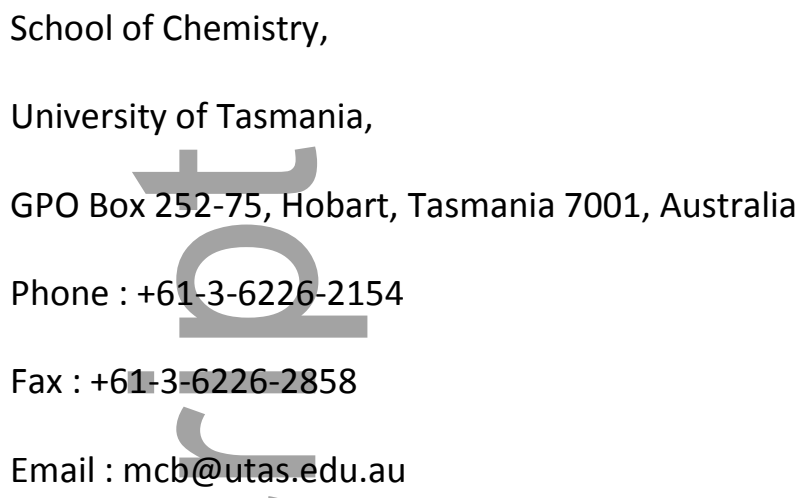

\section{Abstract}

One of the most cited limitations of capillary (and microchip) electrophoresis is the poor sensitivity. This review continues to update this series of biennial reviews, first published in Electrophoresis in 2007, on developments in the field of on-line/in-line concentration methods in capillaries and microchips, covering the period July 2014 - June 2016. It includes developments in the field of stacking, covering all methods from field amplified sample stacking and large volume sample stacking, through to isotachophoresis, dynamic pH junction and sweeping. Attention is also given to on-line or in-line extraction methods that have been used for electrophoresis.

Keywords: extraction, focusing, preconcentration, stacking, sweeping.

1D: one-dimensional, CE: capillary electrophoresis, MCE: microchip capillary electrophoresis, 2D: two-dimensional, LC: liquid chromatography, MEKC: micellar electrokinetic chromatography, AFMC: analyte focusing by micelle collapse, $\boldsymbol{\mu C G E - M E E K C : ~ m i c r o - c a p i l l a r y ~ g e l ~ e l e c t r o p h o r e s i s ~ - ~}$ microemulsion electrokinetic chromatography.

\section{Introduction}

Capillary electrophoresis (CE), and more so, microchip electrophoresis (ME), are regarded as having inferior sensitivity when compared to liquid chromatography - typically 2 to 3 orders of magnitude worse [1]. To overcome this problem, numerous integrated concentration strategies have been developed. Over the last 2 years since the last update, there has again been considerable interest in this topic, with approximately 300 papers published in this time that discuss 'stacking'. While there are papers describing the implementation of these methods in microchips, the reality is that the field is still dominated by the capillary format due to the ease with which experiments can be implemented and the availability of capillary instrumentation.

This review will highlight developments within the field of on-line concentration for electrophoresis, in both capillaries and microchips and follows previous reviews on the topic published [2-6] and compliments other reviews published over this time [7-22]. This review does not aim to be comprehensive, and discusses 150 of the published papers that are of significance to the field

This article is protected by copyright. All rights reserved. 
published between July 2014 and June 2016. Classifications that have been used previously will be kept here and the material has been assembled in the same categories: concentration approaches based on electrophoretic phenomena, will be broadly discussed as 'stacking', while those involving partitioning onto or into a distinct phase, will be considered as 'extraction'. This review will discuss approaches within the context of these two broad areas with the critical requirement that they are integrated in some manner, preferably in-line (performed within the capillary) or on-line (performed in a completely integrated and automated manner). For those who would like a more practical focus, Breadmore and Sänger-Van De Griend propose a decision tree to help select the right method for the right application [23].

\section{Stacking}

\section{Field-strength induced changes in velocity}

\section{Field-amplified sample stacking (FASS) and field-amplified sample injection (FASI)}

FASS is the easiest and the most common approach for sensitivity enhancement in CE. It is achieved by having a significant difference in conductivity between the sample and the BGE. Upon application of voltage, the analytes in the sample zone experience a high electric field strength which triggers fast movement of ions. When the analytes reach the sample BGE interface, they experience a low field strength and they will dramatically slow down and "stack". The sensitivity enhancement in FASS is determined by the ratio of velocities in the sample and the BGE zones. The enhancement in detection sensitivity is usually around 10-20 times when compared to hydrodynamic injection (HDI) of a sample with an equivalent conductivity to that of the BGE $[5,24]$. Despite of its simplicity and ease of applicability, FASS suffers from two major shortcomings. First, that the sample should have a lower conductivity than that of the BGE, thus FASS is limited to samples with a low conductivity matrix, or significantly diluted ones. The other limitation is that the maximum length of the hydrodynamically injected sample plug is limited to about $5 \%$ of the capillary volume. The mismatch of the localelectroosmotic velocities in the BGE zone and sample zone will cause band broadening if a longer sample plug is injected $[25,26]$.

Tu et al [27] described FASS following dispersive liquid-liquid microextraction (DLLME) for the analysis of four piperazinyl phenothiazine drugs in urine and plasma. Volumes of $60 \mathrm{~nL}(6.1 \%$ of the capillary volume) were injected via hydrostatic injection by raising the anodic end of the capillary 21 $\mathrm{cm}$ above its normal position for up to $120 \mathrm{~s}$. The DLLME without FASS enhanced the detection sensitivity by 200 fold while that with FASS provided 2500 fold when compared to conventional CZE and the LODs were down to $80 \mathrm{fg} / \mathrm{ml}$.

Sahore et al [28] reported a novel system for pressure injection and stacking of pre-term birth biomarkers in a microfluidic device. As illustrated in Figure 1, the device features a multilayer PDMS microchip. The fluidic layer had injection and separation channels, and the control layer had a peristaltic pump and four pneumatic valves around the T-intersection to carry out sample injection and plug capture. An unpatterned PDMS membrane was sandwiched between the fluidic and control layers as the actuated component in the pump and valves. The authors studied the effects

This article is protected by copyright. All rights reserved. 
of the peristaltic pump actuation rate and injection time and chose a 50-ms actuation rate and a 30-s injection time that offered a good combination of speed, peak height, and number of theoretical plates (as much as 500,000 plates/m or more). They evaluated four different valve spacing (100, 200,300 , and $400 \mu \mathrm{m}$ ) and chose $200 \mu \mathrm{m}$ as providing the best peak height. Interestingly, when compared to EKI, the HDI scheme enhanced the detection sensitivity by a factor of 4 with efficient elimination of the injection bias.

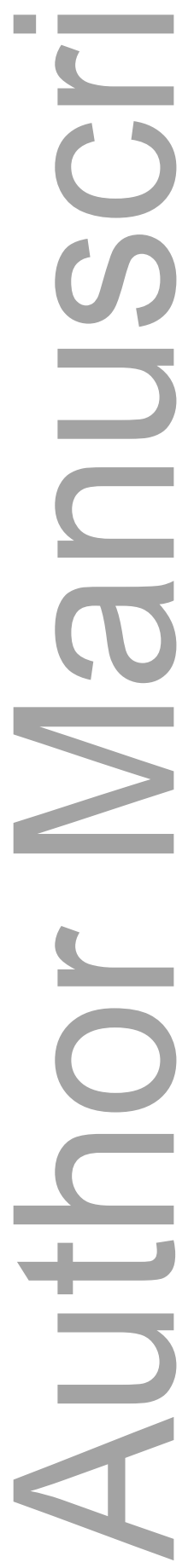

This article is protected by copyright. All rights reserved. 


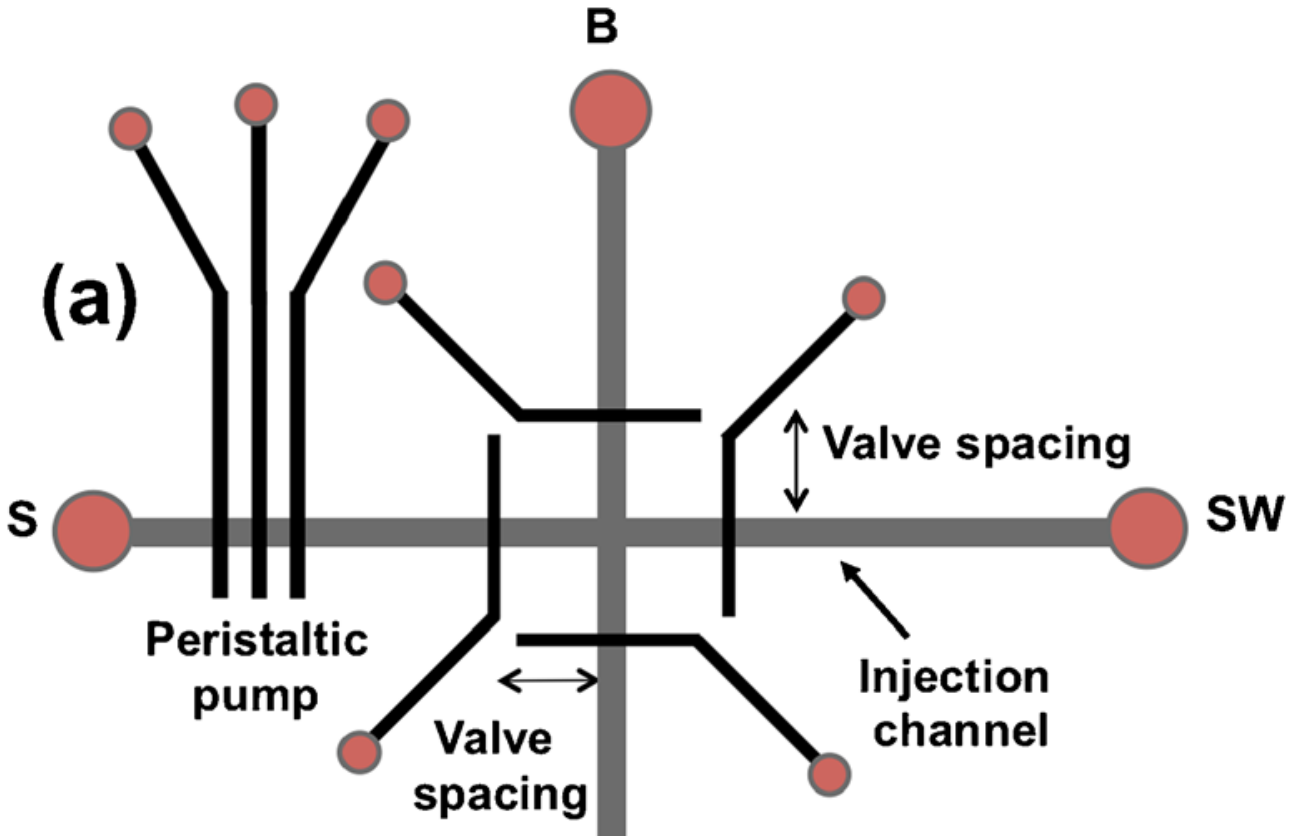

Separation

channel

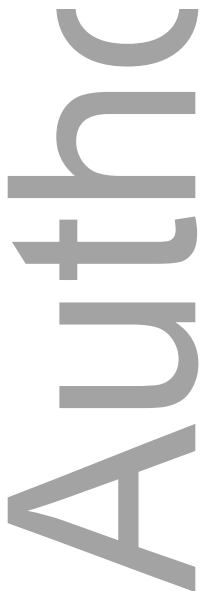

BW

This article is protected by copyright. All rights reserved. 


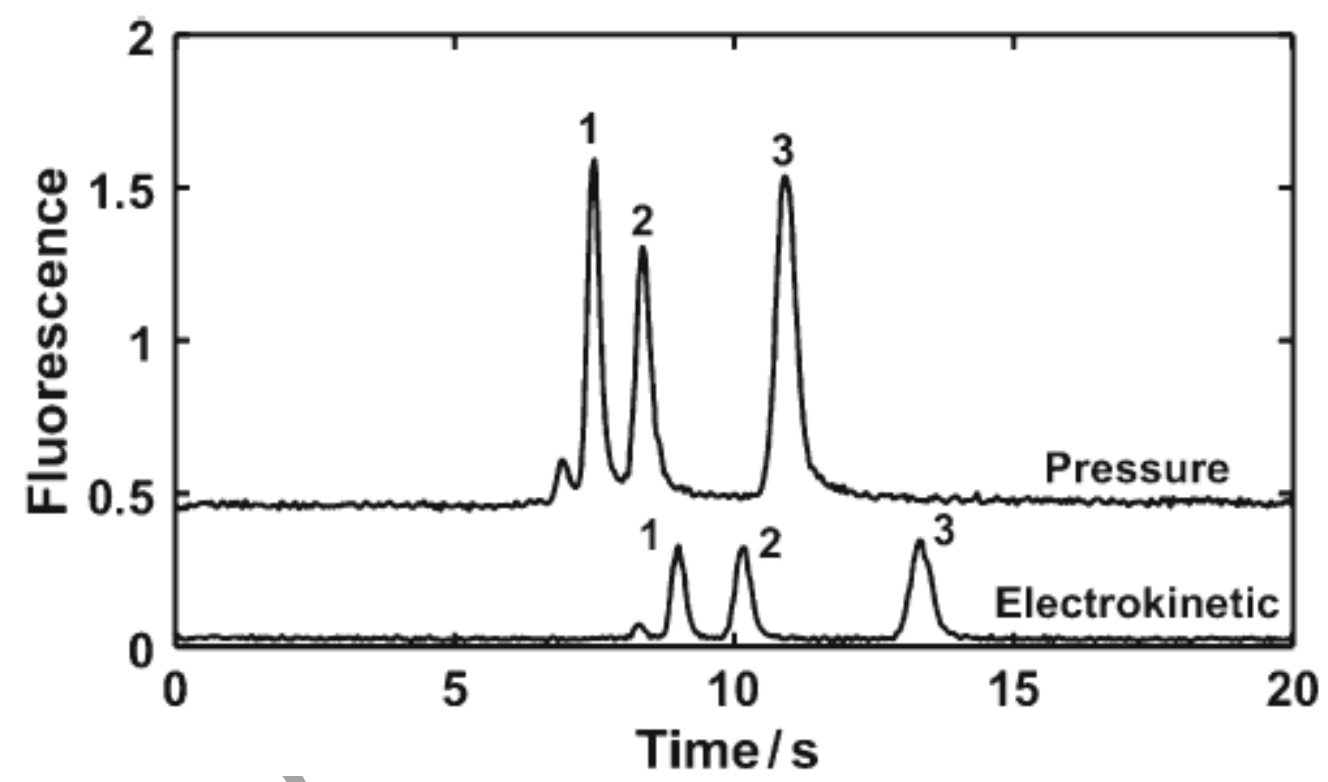

Figure 1: (Upper) Device schematic. (a) Top-down view of the microchip design, showing peristaltic pump and pneumatic valves around the T-intersection. Four different valve spacings were used. $S$ sample, SW sample waste, B buffer, BW buffer waste.

(Lower) Comparison of pressure driven Vs electrokinetic injection with $30 \mathrm{~s}$ injection times.

Electropherograms are offset vertically. For pressure injection, a 50-ms actuation rate and $200-\mu \mathrm{m}$ valve spacing were used. Reprinted from [28] with permission.

While HDI is used for sample introduction in FASS, the sample is loaded by electrokinetic injection (EKI) in FASI. In EKI, ions enter the capillary by their own electrophoretic mobility as well as the EOF [29]. Consequently, more ions will be injected if the electrophoretic mobility of the ion is in the same direction as the EOF. The technique is capable of providing sensitivity enhancement of three orders of magnitude provided a proper adjustment of the direction and magnitude of the analytes and the EOF is carefully considered.

D'Ulivo and Feng used pressure assisted EKI (PAEKI) for injection of positively charged analytes under field-amplified conditions in which a pressure is used to counter the EOF [30]. The sample was injected at $14 \mathrm{kV}$ and a negative pressure of -50 mbar was applied during the injection period ( $2 \mathrm{~min}$ ) to minimise the introduction of sample matrix into the capillary and prolong the high field strength at the tip. Positively charged amino acids could be easily enriched over 3,000 times. When coupled to a Q-TOF system, the PAEKI provided LODs down to $18 \mathrm{pg} / \mathrm{mL}$. Hirokawa and co-workers [31] reported PAEKI for stacking and enantioseparation of the acidic drug verteprofin in artificial urine. Unlike the system described above for positively charged analytes, a negative voltage was used for sample injection and a positive pressure was applied to counterbalance the movement of the EOF which was toward the inlet and would remove stacked analytes from the capillary. A pressure of 0.8 psi with injection voltage of $-10.3 \mathrm{kV}$ were sufficient to immobilize the bulk BGE movement which permitted the injection time to be increased to $2 \mathrm{~min}$. The detection sensitivity was improved by 116 fold when compared to HDI and the LOD was down to $10 \mathrm{ng} / \mathrm{mL}$.

This article is protected by copyright. All rights reserved. 
The highly complementary nature of FASS and FASI make them the first and possibly the most effective stride of sequential stacking mechanisms as will be detailed in section 5 . In addition, the simplicity and ease of applicability of the techniques makes them fairly compatible with various detection modes such as direct [32] and indirect [33] UV, ESI-MS [34], and $C^{4} D[35,36]$. It can also be combined with different CE modes such as capillary gel electrophoresis (CGE) [37] and capillary electrochromatography (CEC) [38, 39]

Sample interface is one of the most important parameters influencing the mass of sample ions that are electrokinetically injected into the electrophoretic system. Gstoettenmayr and co-workers [40] describe a continuous sample flow interface that was constructed using a commercially available Tee connector integrated into a commercial CE to allow direct comparison of the benefit of performing FASI on a flowing sample. The hydrodynamic introduction of sample was minimised by adjusting the liquid levels in the buffer and waste vials allowing injection times of up to $40 \mathrm{~min}$. FASI followed by MEKC was used to compare sample injection from a static system and a flowing stream. The authors demonstrate that by continuously flushing the sample through the interface, the efficiency of FASI is increased, providing significantly enhanced sensitivity. Computer simulations along with experimental studies showed that 4 times more analytes are injected into the capillary than in a static system. Using a flow rate of $588 \mathrm{~nL} / \mathrm{s}$ and injection voltage of $30 \mathrm{kV}$, the detection sensitivity of cationic drugs was improved by 18,000 fold when compared to conventional HDI.

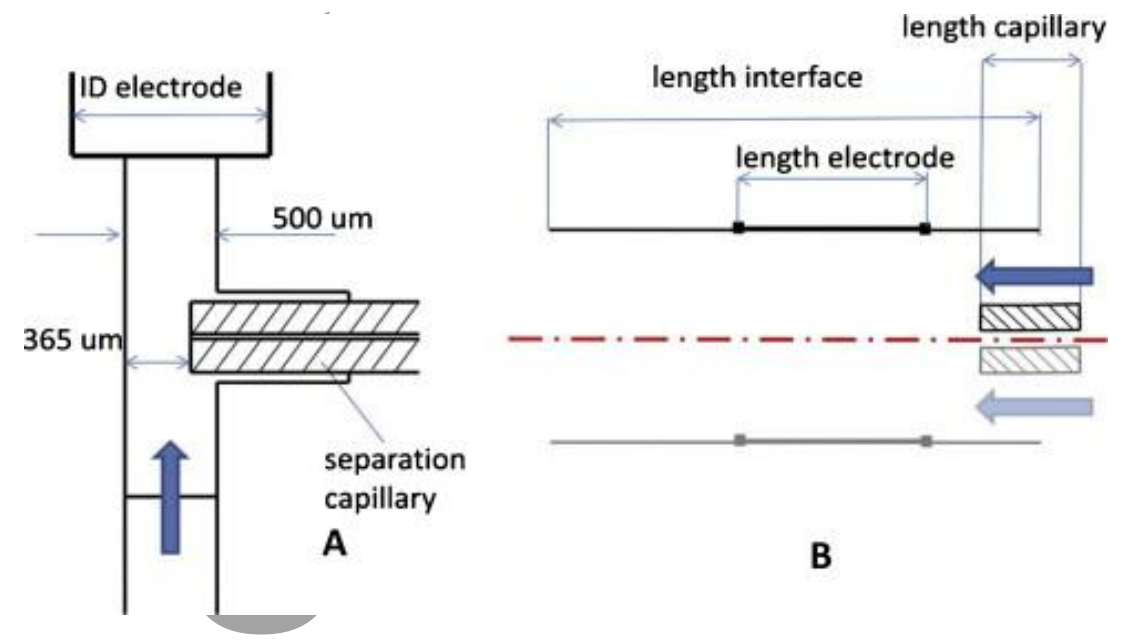

Figure 2: Schematic of the continuous sample flow interface used for experiments (A) and simulations (B). In the experimental setup (A) the ID of the electrode was $1150 \mu \mathrm{m}$ and the separation capillary dimensions were $25 \mu \mathrm{m}$ ID and $365 \mu \mathrm{m}$ QD. For the simulations (B) the interface length was $3 \mathrm{~mm}$, electrode length $500 \mu \mathrm{m}$, capillary ID $50 \mu \mathrm{m}$, capillary OD $150 \mu \mathrm{m}$ and the capillary length was $2 \mathrm{~mm}$. The blue arrows indicate the direction of the flow of liquid. The second electrode is at the outlet of the separation capillary. From [40] with permission.

\section{Large volume sample stacking (LVSS)}

LVSS was developed to allow the injection of large sample volumes which can later be stacked without the peak band broadening effects as observed with FASS. In LVSS, up to $95 \%$ of the capillary volume is hydrodynamically filled with sample which can later be stacked prior to the separation of the analytes. Stacking is usually achieved by polarity switching. In this approach, a reverse polarity is applied to direct EOF towards the inlet of the capillary to allow matrix removal from the injection

This article is protected by copyright. All rights reserved. 
end and stacking of the analytes. Fundamental to this approach is that the electrophoretic mobilities of the analytes must be opposite to that of the EOF.

LVSS with polarity switching has widely been employed for the highly sensitive detection of detection of enzymes (e.g. nucleotide pyrophosphatase/phosphor-diesterase) [41]; antibiotics (e.g. penicillins in milk products) [42]; polyphenols [43] and $\beta$-lactum residues (including amoxicllin, cephalexin, oxacillin, penicillin G, cefazolin and cefoperazone) [44] in natural products; rutin, chlorogenic acid and quercetin in solidaginis [45]; liquiritin, glycyrrhizin, cinnamic acid, gallic acid and protocatechuic acid in Gualou Guizhi granules [46]; quinolones and sulfonamides in aquatic samples (e.g. shrimp and sardine) [47]; copper(I), copper(II) in cells [48], and nitrate in human cerebrospinal fluid [49]. A more complex in-capillary 2, 2-diphenyl-1-picrylhydrazyl (DPPH) assay was developed for fully automated (preconcentration, oxidising reaction, separation, and identification performed in a single capillary) determination of trace antioxidants in natural products using MEKC. Using this developed LVSS method, the enhancement in sensitivity for six antioxidants was increased from 1031 fold when compared to conventional CE method [50].

Highly sensitive proteins analysis was achieved by combining LVSS with FASI. Using LVSS alone, enhancement in sensitivity was observed to be 50-80 fold for albumin, lysozyme, myoglobin and insulin with detection limits of 1.0-2.5 $\mu \mathrm{g} / \mathrm{mL}$. A slight improvement was achieved by hydrodynamically injecting a water plug prior to sample injection $(1.0-1.5 \mu \mathrm{g} / \mathrm{mL})$ to create a low conductivity zone for stacking. However, the detection limit improved impressively by 340-1300 fold when combining FASI with LVSS giving detection limits of $100-500 \mathrm{ng} / \mathrm{mL}$. This method was used for highly sensitive quantification of proteins in urine and serum samples [51].

LVSS without polarity switching (often called LVSEP) can be achieved by the BGE entering the capillary having a different EOF to the sample matrix exiting. It will eventually reach a point which transitions from stacking/matrix removal to separation. Recently, this technique was used for the analysis of nucleotides (cytidine, adenosine, thymidine, uridine, 5-methyluridine, guanosine, xanthosine, and inosine) in serum using CE-UV. Sensitivity enhancements ranged from 1.8 (cytidine) -3.9 (inosine) [52].

\section{Isotachophoretic stacking}

Among all preconcentration methods in electrophoresis, ITP is one of the most robust and powerful because it can concentrate trace of components in a high concentration of matrix ions. In ITP, the sample is concentrated between the leading electrolyte (LE) and the terminating/trailing electrolyte (TE). The difference in mobility between the leader (higher mobility) compared to the terminator (lower mobility) creates a non-uniform electric field upon application of voltage such that ions with a mobility between the leading and terminating ions stack in front of the TE but behind the LE, in descending order based on their mobilities. The length of each zone depends on the concentration of each ion - when the concentration is insufficient to reach the steady-state concentration defined by the Kohlraulsch regulating function then the ion is concentrated as a sharp 'peak' between adjacent ITP zones. ITP is almost unique in that the mechanism induces concentration and separation at the same time.

This article is protected by copyright. All rights reserved. 
Capillary ITP

Oukacine and Taverna reported a method that suppressed fluid flow by using a $22 \%(\mathrm{w} / \mathrm{v})$ polyethylene oxide gel in the outlet vial [53]. Due to the high viscosity of the gel, it physically prevented liquid from exiting the capillary effectively causing the capillary to become closed at that end. This was used for the analysis of amyloid- $\beta$ ( $A \beta 1-40)$ peptide using UV detection with a LOD of $\sim 50 \mathrm{nM}$.

Liu, et al. reported the use of a monolithic column (AAM-based) with counter-flow ITP for protein detection [54]. ITP dispersion using the monolith column was compared with counter-flow ITP in an open channel, with the monolith showing 22 -fold less band broadening than the open channel. This is a potentially attractive approach when combined with long injections to enhance the sensitivity of the ITP zone.

Wegman et al. used ITP to enhance the sensitivity of multiple miRNAs in a single CE separation [55]. A large volume of sample was injected in the capillary between the LE and TE, with the concentrated zone positioned at the capillary inlet prior to separation. A sensitivity enhancement of 100 fold and LODs of $1 \mathrm{pM}$ were achieved in this PCR-free approach for nucleic acid detection. The same group improved the specificity by using locked nucleic acid (LNA) bases [56].

ITP has been of interest to researchers looking at the analysis of intact cells. Dziubakiewicz and Buszewski et al. modified the surface charge of bacteria cells with $\mathrm{Ca}^{2+}$ and used cITP for analysis of six different bacteria (gram positive and gram negative) [57]. ITP focused all of the cells into a single sharp zone $\left(10^{9}-10^{12}\right.$ cells $\left./ \mathrm{mL}\right)$ to enhance detection. While not able to separate individual bacteria, the authors concluded this might be suitable for a simple sterility test. Clarot et al. used cITP for bacteria detection of heterogeneous population of collistin- resistant gram negative bacteria of E.coli, P.aeruginosa, K. pneumonia using UV detection at $288 \mathrm{~nm}$ [58]. Phung et al. introduced a counter-flow EKI for cells to prolong the enhanced field and enhance detection limits [59]. Using LIF and staining the cells with a universal nucleic acid dye, E.coli could be detected down to $78 \mathrm{cells} / \mathrm{mL}$, from a $100 \mu \mathrm{L}$ volume of sample. This was an improvement of 4 -fold compared to without the use of counter pressure.

Gebauer et al. reported an ITP-ESI-MS detection [60] which was subsequently improved with offline SPE followed by CITP-ESI-MS [61]. They were able to detect ibuprofen and diclofenac in water at concentrations of $2 \times 10^{-12} \mathrm{M}$ corresponding to $0.6 \mathrm{fg} / \mathrm{mL}$ diclofenac and $0.4 \mathrm{fg} / \mathrm{mL}$ of Ibuprofen.

Mikus et al. reported the use of on-line column coupled ITP-CZE- triple quadrupole (QqQ) for Vereniciline and its metabolite in human urine with LOD and LOQ in the $\mathrm{ng}-\mathrm{pg} / \mathrm{mL}$ range by injecting unpretreated (and undiluted) urine samples [62]. The same group then compared their method with hydrodynamic open CZE hyphenated with tandem MS for pheniramine and phynylephrine in human urine. [62] They reported that ITP-CZE-ESI-QqQ has higher sensitivity in comparison to the hydrodynamic open CZE-ESI-QqQ which only had a LOD and LOQ in $\mathrm{pg} / \mathrm{mL}$ range for diluted urine [63].

This article is protected by copyright. All rights reserved. 
Kler and Huhn used DMSO as a non-aqueous solvent for ITP of amino acids [64]. DMSO was used to extended the range of analytes that could be studied by influence the acid-base equilibria. This was coupled in-line with CE-MS for the separation of 20 amino acids.

IITP is the terminology used to describe a short ITP stage prior to subsequent electrophoretic separation in the same capillary/channel. Abdul Keyon et al. used tITP-CZE with C4D and UV detection for paralytic shellfish toxins in mussel samples [65]. While only an 8-97 fold improvement in LOD was obtained, the method was more tolerant of salt present in shellfish extracts and could detect saxitoxins close to the regulatory limit.

Hattori and Fukushi performed a fundamental computer study on mobility boost (MB) effect with FASI. In this approach a dilute sample is placed in the inlet vial and migration of counter-ions (in this case anions) into the sample causes a decrease in $\mathrm{pH}$ due to the generation of hydronium from water. This lowers the $\mathrm{pH}$ of the sample protonating weak bases and making them positive and they can be injected by EKI. The LODs of L-histidine and creatinine in a 10000 fold diluted plasma sample were shown to be 0.10 and $0.25 \mathrm{nM}[66]$.

\section{microchips}

On-chip ITP systems are excellent alternatives for classic capillary ones offering much higher flexibility in the setup, although show lower sensitivity and performance. They have been widely used for low-molecular-mass analytes and DNA separations [67-69].

Han et al. demonstrated a method to enhance the reaction kinetics of DNA microarray hybridisation utilising on-chip ITP [70]. Target molecules were concentrated into a narrow ITP zone, and then delivered over 60 spots of 20-27 nt ssDNA oligonucleotide probes. To correct the non-uniform distribution of molecules due to Joule heating and electrokinetic flow instabilities the ITP zone was placed within a narrow channel while the electric field was deactivated for a short time. Experiments showed an 8.2 fold higher signal than the conventional method hybridisation at $100 \mathrm{fM}$ target concentration.

Santiago's group have reported an on-chip system for purification and fractionation of nucleic acids and proteins from $8 \mu \mathrm{L}$ complex samples using ITP [71]. Bidirectional ITP was used for extracellular DNA and protein extraction from human blood serum samples in 25 min (Figure 3). PCR compatible DNA was delivered into one reservoir, while proteins were delivered into another. The low $\mathrm{pH}$ separation conditions was sufficient to exclude albumin in protein extraction. They reported challenges including dealing with the channel surface adsorption of proteins, and nonspecific binding of proteins and DNA.

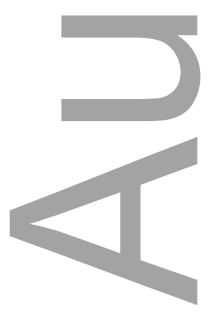

This article is protected by copyright. All rights reserved. 


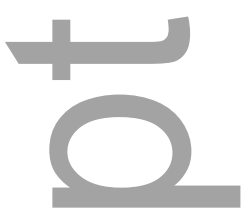

$\square$

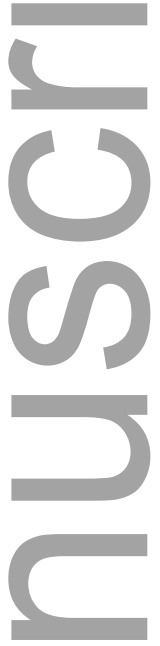

a) Protein elution

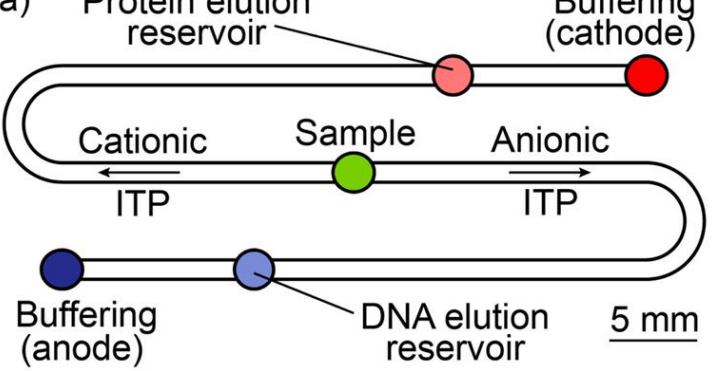

b)

$t_{0}$

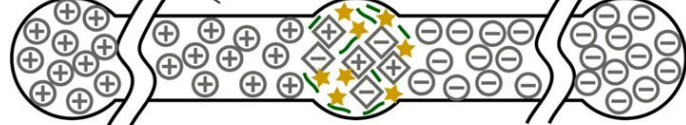

$\mathrm{t}_{1}$

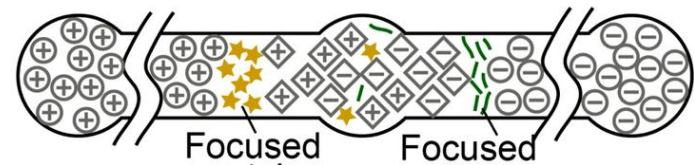

$\mathrm{t}_{2}$

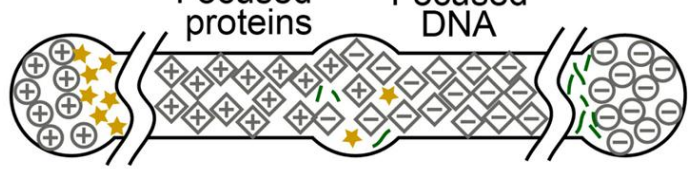

DNA,$T E+$ ion $\diamond T E-$ ion $\diamond$

Proteins $\star L E+$ ion $\oplus$ LE- ion $\Theta$

Figure 3: (a) Chip design for bidirectional cationic and anionic ITP. (b) Schematic of the simultaneous extraction process.

[71]

Integration of ITP into an oxidised nanostructured porous silicon optical biosensor was reported for highly sensitive label-free detection of nucleic acids [72]. The nanostructured material has large surface area and unique photonic properties but has limited applications due to poor sensitivity (typically $\mu \mathrm{M}$ ). Oxidation improves the dielectric insulation for applications based on high electric fields while preserving the morphological characteristics of the nanostructure. Using ITP the highly concentrated DNA zone can be delivered to an on-chip Fabry-Pérot optical transducer prefunctionalised with ssDNA probes. The DNA plug was held stationary on the oxidised nanostructures to facilitate efficient diffusion and hybridisation. Reflective interferometric Fourier transform spectroscopy was used for real time monitoring. The LOD was improved from $1 \times 10^{-6} \mathrm{M}$ to $1 \times 10^{-9} \mathrm{M}$ through ITP.

Kuriyama et al. developed a simple microfluidic platform to control and lyse single cells and then to collect, purify, and focus released cytoplasmic RNA and gDNA by using isotachophoresis. In the ITP system the nuclei and its gDNA content separated from the RNA zone because of the lower electrophoretic mobility. The system was capable of delivering the Cytoplasmic RNA and gDNA into separate reservoirs with no measurable cross-contamination. The whole process was carried out in less than 5 min and off-chip RT-qPCR and qPCR for cytoplasmic RNA and gDNA, were used to demonstrate the utility of the method [73].

An on-chip method for continuous detection of E.coli in water at the point-of-need was demonstrated [74]. Antimicrobial peptides were used to select and label the bacteria because of

This article is protected by copyright. All rights reserved. 
their ability to bind to the bacteria's negatively charged outer membrane. Fluorescently labelled peptides were highly focused in a microfluidic channel using cationic ITP balanced by counter flow. Then by flowing the water sample through the immobilised peptide zone bacteria were rapidly and selectively labelled. They applied this technique for quantitative detection of $E$. coli and showed its stability over an hour.

Gerver et al. introduced a microfluidic Western blot assay using a Tris tricine discontinuous buffer system for analyses of a wide molecular mass range [75]. The analysis was carried out in a straight glass microchannel filled with photoactive polyacrylamide gel. Proteins were separated through a sieving matrix by transient isotachophoresis, then immobilised on gel via UV photocapture (blotting) for in situ antibody probing.

To improve the sensitivity of protein immunoassays a microfluidic device was developed by Khnouf et al. [76]. ITP was used to concentrate the protein in a long horizontal channel that terminated with a protein capture region - antibody-coated magnetic beads or functionalised channel walls. Both the bead-based and direct immunoassay approach were carried out and results showed that the protein was concentrated by a factor of 100 and the limit of detection was in the picomolar range.

Paper-based microfluidic devices have attracted significant interest for point-of-care applications because of the portability and inexpensive substrate material. However, the challenges are the high detection limits and selectivity [77, 78]. Rosenfeld and Bercovici (2014) introduced a novel paperbased analytical device ( $\mu$ PAD) for ITP sample focusing which does not require any cooling [79]. Wax was printed on both sides of the paper and after heating shallow channels ( $\sim 50 \mu \mathrm{m})$ were fabricated on the paper. The advantage of these shallow channels is sufficient dissipation of heat for applying high electric fields. Figure 4 shows the ITP focusing on the paper. By means of this device, $30 \mu \mathrm{L}$ of sample could be processed and 1000-fold peak enhancement in 6 min was achieved.

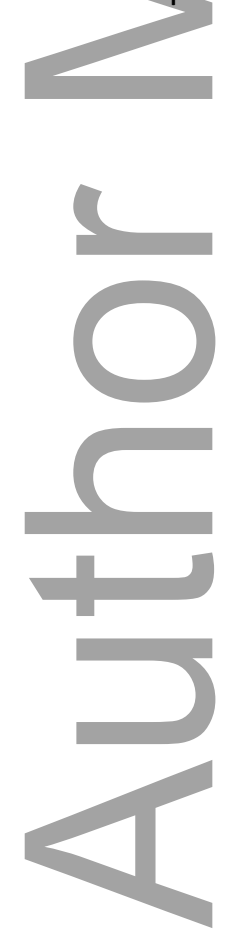

This article is protected by copyright. All rights reserved. 


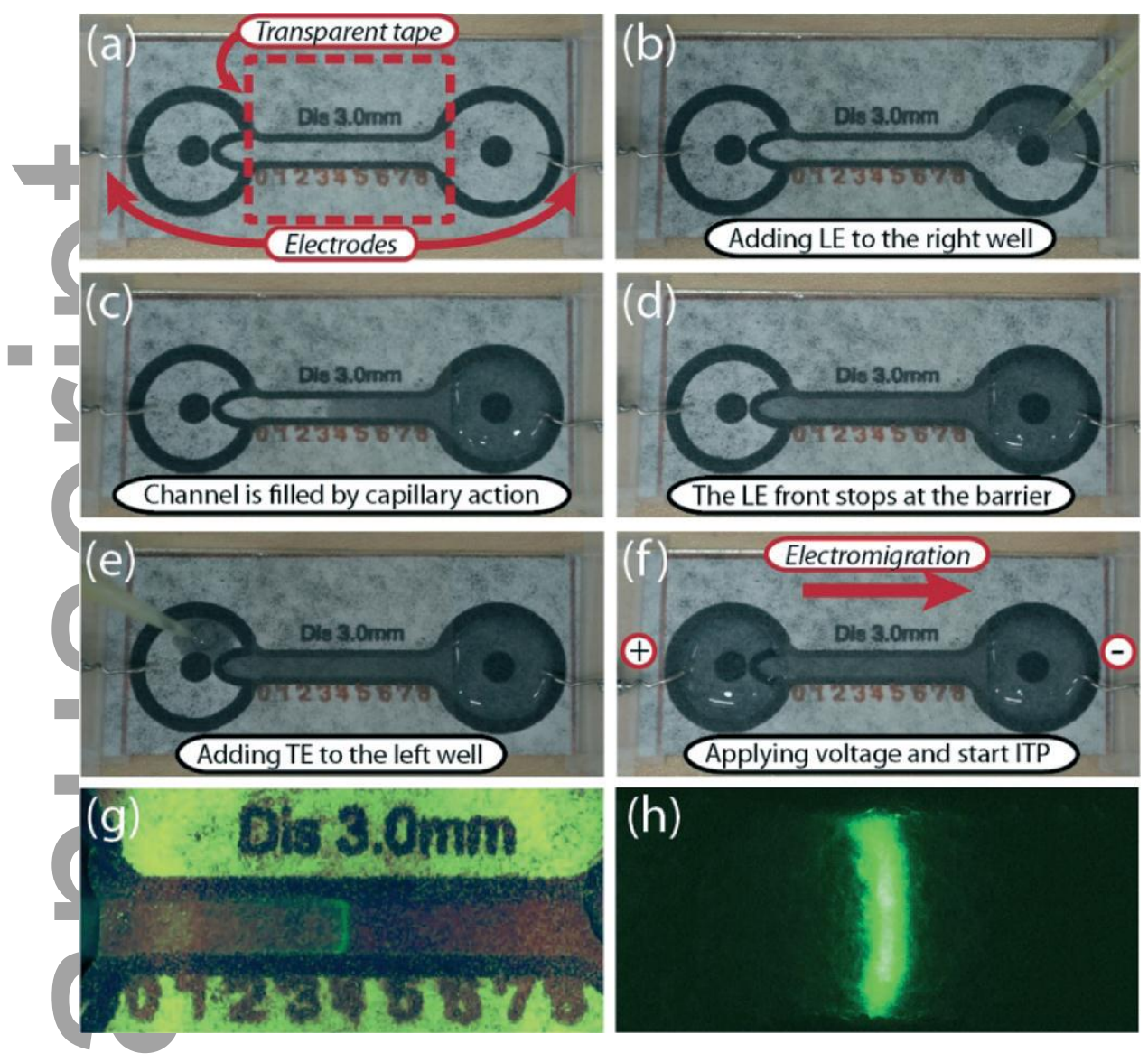

Figure 4: ITP focusing on fabricated $\mu$ PAD (a) electrodes in each of the reservoirs (b) right reservoir was filled with LE solution (c) The channel was filled by capillary action (d) LE stopped at the wax barrier( $10 \mathrm{~min})(\mathrm{e}) \mathrm{TE}-$ sample solution was added to the left reservoir (f) ITP started between LE and TE. (g) fluorescence image of ITP focusing by a consumergrade camera (h) fluorescence image of ITP focusing under a microscope [79]

Li et al presented a paper-based isotachophoresis (ITP) device for focusing DNA samples [80]. Both ssDNA and dsDNA with lengths between 23 to $1517 \mathrm{bp}$ were focused by more than two orders of magnitude within $4 \mathrm{~min}$ in a circular paper channel fabricated by origami (Paper folding). The low applied voltage (18 V) appropriate for point-of care (POC) applications was able to generate a high electric field to focus the sample between the leading and trailing electrolyte.

\section{Chemically induced changes in velocity}

\section{Dynamic pH junction}

This stacking approach concentrates via a change in $\mathrm{pH}$ between the BGE and sample. It works when an analyte's ionisation state changes when moving to a different $\mathrm{pH}$, which changes the electrophoretic mobility and can cause concentration and focusing. This was first applied to CE by Aebersold and Morrison [81] and termed dynamic pH junction in 2000 by Britz-McKibbin et al. [82]. However, this preconcentration technique is also known as a moving neutralisation boundary [83] and is a subset of moving reaction boundaries [84]. Even though the mechanism of dynamic $\mathrm{pH}$ junction is well studied, the amount of molecules injected compared to the amount captured by the dynamic $\mathrm{pH}$ junction focusing is sometimes not clear. Wang et al. [85] studied the capture efficiency

This article is protected by copyright. All rights reserved. 
of nicotinic acid for the two types of dynamic $\mathrm{pH}$ junctions (using low and high $\mathrm{pH}$ as a BGE) by CE with both UV and ESI-MS detection. The results revealed the capture efficiency easily exceed the $95 \%$ of target molecule.

Both dynamic $\mathrm{pH}$ junction and FASS/FASI can be combined for further enhancements when the sample has a different $\mathrm{pH}$ and conductivity. Li et al. [86] developed and validated a method to characterise metachromatic leukodystrophy (a rare and severe genetic disease) monitoring the inhibitor adenosine-3',5'-diphosphate by CE with UV detection. Using $5 \mathrm{mM}$ phosphate at $\mathrm{pH} 7.4$ as a sample matrix, $75 \mathrm{mM}$ phosphate at pH 5.6 as a BGE, and cationic surfactant in both buffers to reverse the EOF, they achieved a LOD improvement of the method by 46 -fold.

Ludwig et al. [86] demonstrated the identification of over 2313 phosphorylated peptides in a singleshot using CZE-ESI-MS/MS with dynamic $\mathrm{pH}$ junction. Sample was prepared in $10 \mathrm{mM}$ ammonium acetate $(\mathrm{pH} \sim 6.0)$ and the BGE was $5 \%$ of acetic acid ( $\mathrm{v} / \mathrm{v}, \mathrm{pH} \sim 2.4)$ they increased the sensitivity by approximately 10 -fold. They also demonstrated that the dynamic $\mathrm{pH}$ junction method produced better enrichment performance than the typical stacking method when the sample loading volume was very large [87]. Finally, they demonstrated that CZE-MS/MS can produce better peptide sensitivity than UPLC-MS/MS, outperforming UPLC for 2-200 ng sample loading amounts.

CZE-ESI-MS/MS with pH junction was used by Zhu et al. [88] used to increase injection volume for detection of trace amounts of host cell protein impurities in recombinant therapeutics. They tested 3 different sample buffer $\mathrm{pH}$ values $(6.5,8.5$ and 10.0 ) in a BGE of $5 \%$ acetic acid ( $\mathrm{v} / \mathrm{v}, \mathrm{pH} \sim 2.4$ ), with the electropherograms from $0.1 \mathrm{mg} / \mathrm{mL}$ Escherichia coli digests shown in Figure 5 . An increase in resolution and sharpening of late migrating peptides was observed at higher $\mathrm{pH}$. However, they suggested to use $\mathrm{pH} 8.5$ to avoid hydrolysis of the capillary coating. This approach generated approximately five times higher base peak intensity and more peptide identifications for low-level spiked proteins.

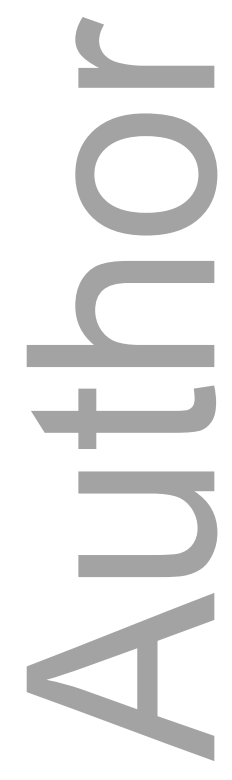

This article is protected by copyright. All rights reserved. 


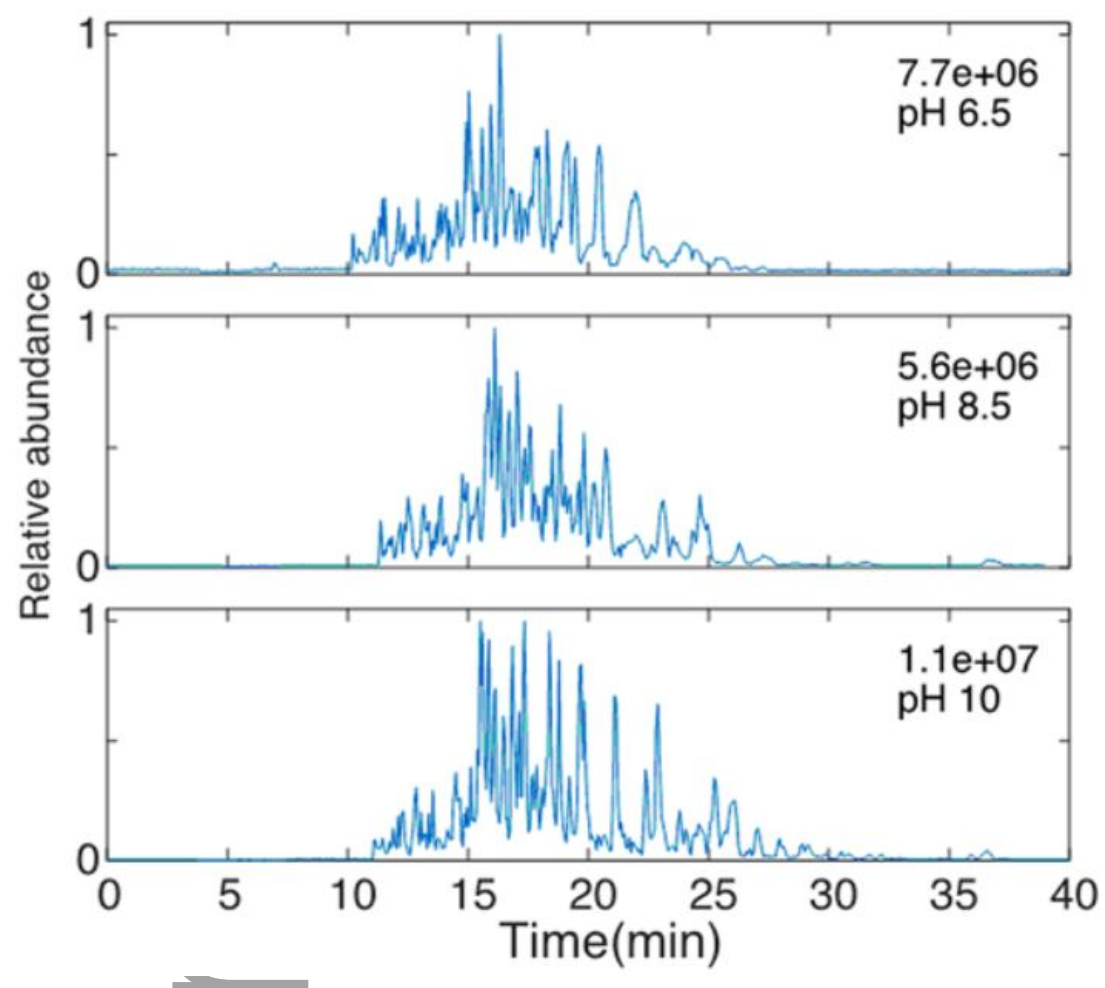

Figure 5: Base peak electropherograms of Escherichia coli digests by CZE-MS coupled with $\mathrm{pH}$ junction injection with different $\mathrm{pH}$ sample matrix ( $\mathrm{pH} 6.5, \mathrm{pH} 8.5$, and $\mathrm{pH} 10)$. Maximum normalised level noted for each electropherogram. Reproduced from [88] with permission.

Peak enhancing is one of the main advantages in stacking approaches, however peak sharpening is a benefit that is often not considered. Umeda et al. [89] achieved up to 12 -fold peak height enhancement and zone sharpening of peptides by employing dynamic $\mathrm{pH}$ junction in pressurised $\mathrm{CEC}$. They demonstrated selective stacking of specific types of angiotensin protein by tunning the $\mathrm{pH}$ of the BGE. The differences in pl of three different angiotensins ( $p l 6.74,8.14$ and 8.80) causes peak enhancement only for one protein that changes their leading ionisation ( $\mathrm{pl}$ 6.74) whilst the other will not be sharper. Consequently proteins with lower pl than the working $\mathrm{pH}$ of the BGE will get more concentrated and sharper, distinguishing out then from those with higher pl.

\section{Association with pseudo-phases}

\subsubsection{Association with pseudo-stationary phases}

EKC enables electroseparation of neutral, cationic and anionic compounds according to their interaction with a pseudostationary phase [90]. This interaction can also be used for concentration through sweeping - the accumulation of the analytes at the front of the pseudo phase [91] - and collapse - the release of micelle-bound analytes by micelle collapse (AFMC) [92] and micelle to solvent stacking (MSS) $[93,94]$.

\subsubsection{Sweeping}

This article is protected by copyright. All rights reserved. 
In sweeping-EKC, a long plug of pseudo-phase free sample is injected hydrodynamically into a capillary filled with separation electrolyte containing the pseudo-phase. Upon application of the voltage, the pseudo phase sweeps through the injected zone and concentrates the analytes into a narrow zone. Sweeping is applicable to charged and non-charged analytes as well as suitable for samples of low and high ionic strengths. Neutral micelles can also used but are only applicable to charged analytes. Sweeping can be combined easily with other stacking techniques such as AFMC, MSS, FASI, and dynamic pH-junction, see Section 5.1.

Sweeping [95-104] was applied to investigate drugs [95, 99, 102], hydrophobic cosmetic additives [101], cationic antibiotics [97], hydrogensulfide [98], plasticisers [100], herbicides [96, 103], and stimulants [104]. The samples were wastewater, cosmetic products, food and beverage products (including alcoholic drinks), and human urine and plasma. The analysis of the complex samples required sample preparation including solid-phase extraction (SPE) [97, 99], liquid-liquid extraction (LLE) [101], solid-liquid extraction [96], protein precipitation [95, 97], derivatisation [98], dispersive liquid-liquid microextraction [100, 103], and electrophoretic concentration [102]. The sample preparation was beneficial to further improve on detection sensitivity, although in some cases resulted in a tedious and prolonged analytical workflow. All papers applied UV-detection (200-375 $\mathrm{nm}$ ) and on uncoated fused-silica capillaries. In one case, a bubble cell with an extended optical pathway of $150 \mu \mathrm{m}$ was employed [97]. The negatively charged SDS micelles was the most common used pseudo phase; two reports added the neutral polymer of polyethylene oxide (PEO) [101] or $\beta$ cyclodextrin [100] as pseudo phases to improve on analyte enrichment or separation. The separation electrolyte was modified with $0.1 \%$ PEO to increase the viscosity and enhance the sweeping efficiency or with $5 \mathrm{mM} \beta$-cyclodextrin to improve the analyte resolution. A short chain alkyl imidazolium ionic liquid (IL) was also added to the separation electrolyte as micelle forming agent [95]. The injected sample plugs, expressed as $\%$ length to the detection window, ranged from $3.5 \%$ to $84 \%$, which resulted in improvements in the analyte detection sensitivity by factors 2 to 636 compared to typical injection.

\subsubsection{Analyte focusing by micelle collapse (AFMC) and micelle to solvent stacking (MSS)}

In-line sample concentration by AFMC is suitable for neutral as well as charged analytes while MSS has only been applied to charged analytes. In both techniques, the initial configuration was that the sample is prepared in a micellar solution with a surfactant concentration slightly above the critical micelle concentration $(C M C)$. The analytes are released from the micelles when they move from the sample to the BGE where they are diluted and the analytes are concentrated. Dilution can be achieved by preparing a sample with higher conductivity than the separation electrolyte [92]. In MSS, the micelle has an opposite charge to the analyte. The effective electrophoretic mobility of the analyte is reversed at an organic solvent rich zone, and again the analytes are released when the micelle collapses. The reversal in mobility causes them to focus around the sample/solvent boundary. The organic solvent rich zone may be the separation electrolyte modified with organic solvent or a plug of organic solvent rich solution injected appropriately.

This article is protected by copyright. All rights reserved. 
In AFMC [95, 105-109], the analytes were neutral UV absorbents [107, 109], cationic herbicides [108], neutral pesticides [108], drugs [95], vitamins [106], neurotoxin [105], amino acid [105] and sugar [105]. The samples were sunscreen, river water, human blood and urine, and food products. The sample preparations included LLE [107, 109], drying and reconstitution [108], protein precipitation $[95,106]$, and ultrasound-assisted extraction [105]. The pseudo-phase was typically SDS at concentration of 5-7.5 mM [107-109] or 1-butyl-3-methylimidazolium bromide at a concentration of $3 \mathrm{~mol} / \mathrm{L}[95,105,106]$ as the micelle forming agent in the sample. In all papers UV detection at 200-254 $\mathrm{nm}$ was used with the exception of one report applying a novel electrochemical detector based on a protein/IL modified glassy carbon electrode [106]. The injected sample plugs, expressed as \% length to the detection window, were from $0.62 \%$ to $22.3 \%$ which resulted in an improvement in the sensitivity by 2 to 75 compared to a typical injection.

AFMC was achieved by the sample having a conductivity of around $3 x$ higher than the separation electrolyte $[95,105,106]$ or by injection of a separation buffer with $30 \%$ acetonitrile [108]. Interestingly, the conductivity of the sample in $[107,109]$ was lower (i.e., $1154 \mu S$ ) than the separation electrolyte (i.e., $1778 \mu \mathrm{S}$ ). This suggests that the dilution of the micelles did not occur by conductivity differences. The concentration of electrolyte in the sample and separation electrolyte was 10 and $100 \mathrm{mM}$ Tris $\mathrm{HCl}$, respectively. Chloride is the counter-ion of Tris and has a higher electrophoretic mobility than SDS. The dilution of the SDS in the sample might have had occurred because of a concentration adjustment by the Kohlrausch Regulation Function.

In MSS [110-113], the cationic analytes included antihistamine [113], acetylcholinesterase inhibitor [111], tricyclic antidepressant [111], local anaesthetic [111], antiplatelet drug [111], calcium channel blocker [111], phthalate plasticiser [110], and nonsteroidal triphenylethylene antiestrogen and its metabolites [112]. The samples were human plasma, river water, and paediatric pharmaceuticals. The sample preparation for the analysis of the plasma samples and pharmaceuticals required protein precipitation and LLE, respectively. The river water was dried and directly reconstituted in sample diluent prior injection. All articles used SDS micelles with a concentration of 5-114 mM. The high 114 mM SDS was due to the use of a microemulsion as sample diluent [111]. The detection was performed by UV (200-214 nm) or by C4D. The injected sample lengths, expressed as \% length to the detection window, ranged from 8.7 to $65.4 \%$. This translated to an improvement in detection sensitivity by a factor of 14 to 200 compared to typical injection.

MSS was by injection of the sample in a capillary previously conditioned with a separation electrolyte containing high concentrations of organic solvent (i.e., $55 \%$ methanol or $40 \%$ acetonitrile) [110]. In non-aqueous CE, another configuration of MSS was employed where the micellar solution was injected prior to the methanol rich sample solution $[112,114]$. The positively charged tamoxifen and metabolites in the methanol rich sample zone migrated to the micelles zone where they were captured and immediately transported back to the methanol rich sample zone. The transport caused the release of the micelle-bound analytes at boundary between sample and micellar solution and eventual concentration of analytes at this boundary.

This article is protected by copyright. All rights reserved. 


\section{Physically induced changes in velocity}

Generating an electric field strength gradient for electrokinetic sample preconcentration can be achieved near nano-microchannel interfaces (NMIs). Under an applied electric field, NMIs induce ion concentration polarisation due to their preferential ionic transport behaviour. Steeper electric field strength gradients result in faster and higher enrichment factors. Other factors like the electrolyte ionic strength and the applied electric field also contribute to the speed and magnitude of enrichment.

ent.

NMIs exhibit preferential ionic transport of counter-ions. As the dimensions of the nanochannel approach the electric double layer (EDL) thickness, the Debye length, an overlap occurs and the current through the nanochannel is mainly carried by the counter-ion. Co-ions are excluded from the nanochannel resulting in an enrichment zone on one side and a depletion zone on the other. The selectivity of the nanochannel and the speed by which ion concentration polarization (ICP) can be achieved is affected by the nanochannels pore size and surface charge density, and the background electrolyte ionic strength and $\mathrm{pH}$.

To understand the nature of ICP, a real-time dual-loop electric current measurement was proposed by Chung et al.[115] for monitoring the electrokinetic trapping of molecules. This approach reveals more information than can be acquired using fluorescence detection and can be used to determine the lowest applied voltage that can be used to achieve electrokinetic trapping. The device featured two microchannels in PDMS layer bound to a glass layer containing 80 nanochannels that are $40 \mathrm{~nm}$ deep and perpendicular to the microchannels in the PDMS layer. All experiments were done in $1 \mathrm{mM}$ phosphate buffered saline to ensure EDL overlap. The i-V curves were used to describe the ICP behavior. The preconcentration process was explained by five stages; the ohmic, limiting, overlimiting, separating current, and plug appearing regimes as illustrated in Figure 6 . The authors identify at least 3 uncertainty factors that make each device different; the bonding of PDMS to the glass slide, salt gradients inside the nanochannels, and variations in the nanochannel depth due to imperfect etching. These differences were reflected in the $\mathrm{i}-\mathrm{V}$ curves for the right and left loops; the differences became more profound beyond a certain applied voltage marking the start of the separating current regime.

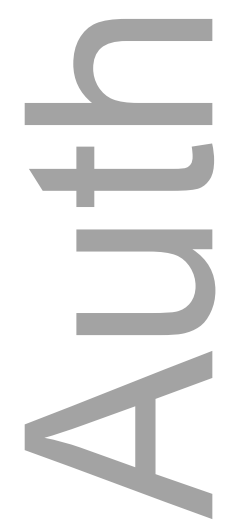

This article is protected by copyright. All rights reserved. 
A

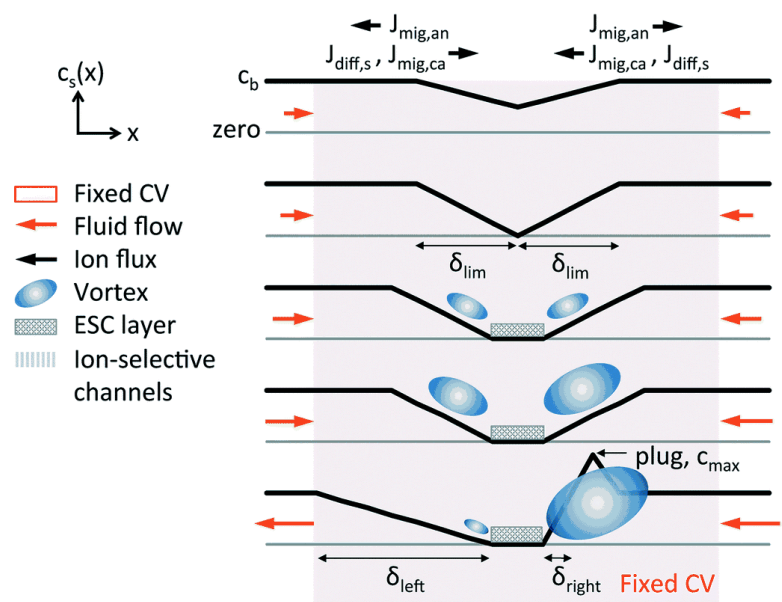

(a) Ohmic regime: $I_{\text {right }}=I_{\text {left }}<I_{\text {lim }}$ $\delta_{\text {right }}=\delta_{\text {left }}=\delta_{\text {lim }}, D_{\text {right }}=D_{\text {left }}=D_{\text {lim }}$ $\mathrm{Q}_{\text {right }}=\mathrm{Q}_{\text {left }}, \mathrm{Q}_{\mathrm{n}}=\mathrm{Q}_{\text {left }}+\mathrm{Q}_{\text {right }}$

(b) Limiting current regime: $I_{\text {right }}=I_{\text {left }}=I_{\text {lim }}$ $\delta_{\text {right }}=\delta_{\text {left }}=\delta_{\text {lim }}, D_{\text {right }}=D_{\text {left }}=D_{\text {lim }}$ $Q_{\text {right }}=Q_{\text {left }}, Q_{n}=Q_{\text {left }}+Q_{\text {right }}$

(c) Overlimiting current regime: $I_{\text {right }}=I_{\text {left }}>I_{\text {lim }}$ $\delta_{\text {right }}=\delta_{\text {left }}=\delta_{\text {lim }}, D_{\text {right }}=D_{\text {left }}>D_{\text {lim }}$ $\mathrm{Q}_{\text {right }}=\mathrm{Q}_{\text {left }}, \mathrm{Q}_{\mathrm{n}}=\mathrm{Q}_{\text {left }}+\mathrm{Q}_{\text {right }}$

(d) Separating current regime: $I_{\text {right }}>I_{\text {left }}>I_{\text {lim }}$ $\delta_{\text {right }}=\delta_{\text {left }}=\delta_{\text {lim }}, D_{\text {right }}>D_{\text {left }}>D_{\text {lim }}$ $\mathrm{Q}_{\text {right }}>\mathrm{Q}_{\text {left }}, \mathrm{Q}_{\mathrm{n}}=\mathrm{Q}_{\text {left }}+\mathrm{Q}_{\text {right }}$

(e) Plug appearing regime: $I_{\text {right }}>I_{\text {lim }}>I_{\text {left }}$ $\delta_{\text {right }}<\delta_{\text {lim }}<\delta_{\text {left }}, D_{\text {right }}>D_{\text {left }} \approx D_{\text {lim }}$ $\mathrm{Q}_{\text {right }} \approx \mathrm{Q}_{\text {left }}, \mathrm{Q}_{\mathrm{n}}=\mathrm{Q}_{\text {right }}-\mathrm{Q}_{\text {left }}$

B

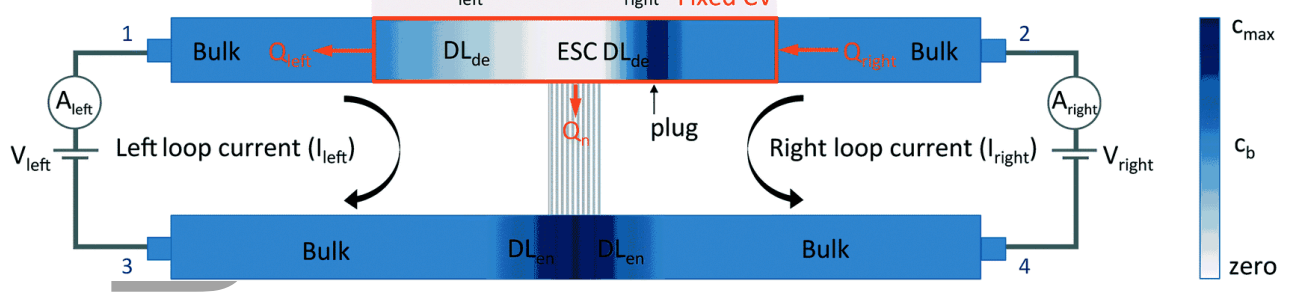

Figure 6: Characteristics of the five stages during the preconcentration process, determined by using control volume analysis for fluid flows. A. A schematic of ion concentration profiles and field-induced vortices in the upper microchannel at different stages of the preconcentration process. B. A simplified schematic illustrating in/outflows for a fixed CV and ion concentration polarisation in the plug-appearing regime. Reproduced from [115] with permission.

\section{Fabricated nanochannels}

Standard lithography methods for producing straight nanochannels with well-defined dimensions are important for understanding ionic transport. A nanochannel with negatively charged surface favors the transport of cations. However, reversed ion selectivity can be achieved if enough salt concentration gradient is maintained across the nanochannel and the applied voltage is adjusted. The nanopore side exposed to high ionic strength will not show EDL overlap and ions can freely transport through the nanopore till they reach an area with low enough electrolyte ionic strength for the EDL to grow and overlap. The reversal of ionic selectivity was demonstrated for short charged nanopores by Yeh et al.[116] When the direction of the applied voltage and the salt gradient is the same, i.e. higher ionic strength on the anodic side of the nanopore, the nanopore is cation selective. But, when a moderately small negative bias is applied, high ionic strength on the anodic side, the nanopore becomes anion selective. The authors suggested that under these conditions, the ionic flux of cations is in the same direction as the anions but at lower magnitude, which makes the nanopore anion selective. Trapping of biomolecules can be achieved in a reversed magnified electric field near the cathodic side of the nanopore when the directions of the applied concentration gradient and electric field are identical.

Different geometry and designs were attempted to increase their concentration efficiency. A "ringlike" design was proposed for concentrating nanoparticles and featured four radial nanochannels that are 100-nm deep.[117] Standard photolithography and etching technique was used to fabricate the nanochannels in silicon. 50-nm green fluorescent polystyrene nanobeads were enriched by $800-$ fold within $1 \mathrm{~h}$ on the cathodic side of the nanochannels. Cathodic preconcentration allows stable

This article is protected by copyright. All rights reserved. 
operation for extended period of time. The radial design is also supposed to offer higher stability than that observed in straight nanochannels due to the symmetrical distribution of the electric field. Low applied voltage was used, $50 \mathrm{~V}$, which is suitable for portable devices. However, one major drawback of the proposed method is that in order to achieve EDL overlap in the 100-nm deep nanochannels, all experiments were done in deionised water. Application of the method to biological samples is questionable.

Funnel-shaped nanochannels showed ion current rectification inversion above a threshold voltage that marks the transition from the under-limiting to over-limiting current.[118] The inversion can be attributed a shift of the system resistance beyond the threshold voltage. Under overlimiting conditions, ions are depleted at the anodic side of negatively charged nanochannel and the depleted region outside the nanochannel will control the rectification direction.

Low detection limits for protein $(2.5 \mathrm{pg} / \mathrm{mL}$ of BSA) were reported using a nano/microfluidic device under applied electric field.[119] The device comprised microchannels in PDMS and nanochannels ( $27 \mathrm{~nm}$ deep) fabricated by UV ablation in polycarbonate sheets. The sample protein was adsorbed on gold nanoparticles then an exact amount of labeled protein (FITC-labeled DSA) was added to saturate the surface of the AuNPs. The excess free labeled protein in the solution was enriched at a $\mathrm{NMI}$ and the fluorescence intensity is measured. The amount of free protein is proportional to the amount of the protein in the sample. The adsorbed fluorescent protein does not interfere with the measured signal due to nearly complete quenching through strong electronic interaction with the AuNP. For trace concentrations of protein $(0.1 \mathrm{ng} / \mathrm{mL})$, the detection limits achieved were 1000 times lower than the most sensitive commercial protein quantification methods. Regarding applicability to biological samples, the experiments were done in $10 \mathrm{mM}$ phosphate buffer which is nearly 10 times less than the ionic strength of plasma. Experiments with human serum were done after 1000 times dilution step. The results presented in the fluorescence plot indicate 3.5 -fold enrichment after $800 \mathrm{~s}$. A more serious problem is that the method is not specific to a certain type of protein, i.e. any protein will adsorb to the AuNP leaving an equivalent amount of the labeled free protein in solution.

\section{Nafion $^{\mathrm{TM}}$ and polymer membranes}

Nafion $^{\mathrm{TM}}$ is by far the most frequently used nanoporous membrane used for electrokinetic concentration. Yoon et. al applied a buffer drain technique to increase the concentration of the virus in the reservoir [120]. The inside of the microchannel was coated with Nafion ${ }^{\mathrm{TM}}$. Under applied electric field, charged molecules and particles were blocked from entering the microchannel by ICP while the buffer was drained by pressure. Using this approach, $75 \mu$ l of buffer was successfully drained from a $100 \mu \mathrm{l}$ sample, resulting in a 4-fold increase in influenza hemagglutinin concentration in the reservoir. This method was novel but the sensitivity and selectivity are two main concerns.

Nafion has been widely used in microfluidic paper-based device ( $\mu P A D)$ for sample preconcentration.[121-127] Phan and co-workers developed a $\mu$ PAD by simply integrating microporous paper and nanoporous nafion membrane and then laminating with plastic film without

This article is protected by copyright. All rights reserved. 
printing hydrophobic materials such as wax, the schematic was shown in Figure 7, this device showed a 60-fold concentration enhancement for fluorescent dye within 200 s.[121]

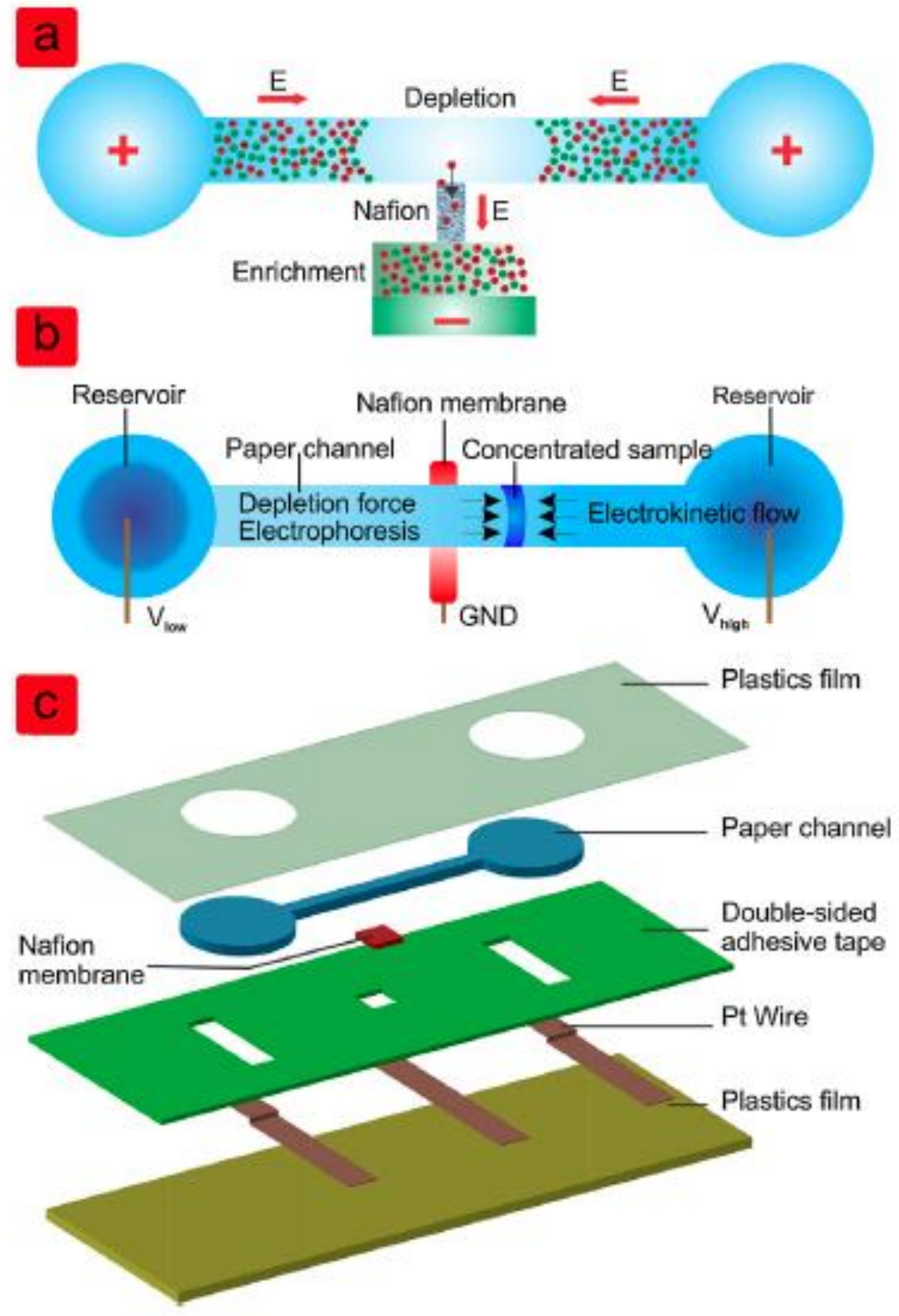

Figure 7: Paper-based analytical device for sample concentration using ion concentration polarisation: (a) ICP phenomenon occurred on a straight paper channel under the influence of an applied electric field across the Nafion junction, which only allows cations to pass through its nanopores. The cathode is acted as an unlimited-anions providing source; (b) working concept showing the combination mechanism of three different forces in the device; (c) device

This article is protected by copyright. All rights reserved. 
structure containing several layers fabricated with different materials. Reproduced from [121] with permission from the Elsevier.

Yang et al. compared a wax printed $\mu$ PAD with straight and convergent channels and a Nafion ${ }^{\mathrm{TM}}$ membrane [126]. The channel width was $2 \mathrm{~mm}$ and the convergent width was varied from 0.25 to $1.5 \mathrm{~mm}$. A convergent width of $1 \mathrm{~mm}$ was chosen as the optimum compromise between enhanced enrichment due to nozzle-like effect in the narrower dimension and higher conductivity in the wider dimensions. The convergent channel was more efficient in concentrating fluorescein; achieving 20fold enhancement within $130 \mathrm{~s}$ compared to a 10-fold enhancement within $180 \mathrm{~s}$ for the straight channel. A MPAD with branching microchannel and incorporating a Nafion ${ }^{\mathrm{TM}}$ membrane was reported for concentrating negatively charged species [125]. The main straight channel split into two daughter channels with different widths, 3 and $0.4 \mathrm{~mm}$ wide. The Nafion ${ }^{\mathrm{TM}}$ membrane was positioned at the bifurcation. Steady flow was maintained passively for $10 \mathrm{~min}$ by connecting the daughter channels with expanded regions. The developed ICP resulted in up to 33-fold enrichment of the Alexa Fluor 488 and 20-fold for 488-labeled BSA fold prepared in $1 \mathrm{mM} \mathrm{NaCl}$. A $\mu$ PAD comprising one, two and three convergent channels were evaluated for preconcentrating negatively charge species using Nafion $^{\mathrm{TM}}$ membrane (Figure 8) [128]. The channel dimensions were $50.0 \mathrm{~mm} \times$ $2.0 \mathrm{~mm}$ (length $X$ width), with a $1.0 \mathrm{~mm}$ convergent section. The Nafion ${ }^{\mathrm{TM}}$ membrane was placed $5.0 \mathrm{~mm}$ from the convergent section. Both, ICP and the geometry of the channels contributed to the focusing effect. Enrichment factors for $10^{-5} \mathrm{M}$ fluorescein were 20-, 60- and 140-fold for the single-, double-, and triple-channel design, respectively. In the multi-channel designs, the sample is concentrated not only as a result of the ICP and geometry-focusing effect induced in each convergent channel, but also by a flow-focusing effect in the intersection region between the channels. Gong et al. demonstrated direct DNA analysis in a $\mu$ PAD with a patterned nafion membrane [122]. Hepatitis B virus DNA fragments were simultaneously preconcentrated, separated, and detected in 10 min with a LOD of 150 copies/mL without prior viral local amplification. The DNA integrity of sperm cells in raw human semen samples was also assessed to evaluate the male fertility. To improve the sensitivity of a $\mu P A D$ to detect biomarkers with low concentrations in body fluids, Yeh et.al proposed a method for enhancing the ICP by reducing the $\mu$ PAD channel depth using a two-sided wax-printing process [127]. The channel was printed by two-sided wax printing giving a depth of only $50 \mu \mathrm{m}$, which featured a lower EOF velocity, the ability to apply a higher voltage and greater confinement of the concentrated sample, thus achieved a higher enhancement. It was shown that while a conventional PPAD preconcentrated fluorescein by a factor of 130-fold, the shallow-channel $\mu \mathrm{PAD}$ achieved a preconcentration factor of 944-fold.

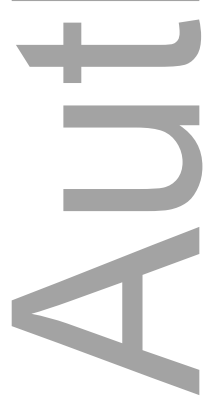

This article is protected by copyright. All rights reserved. 
(a)

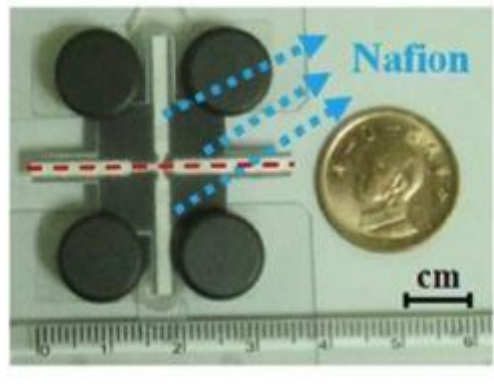

(b)

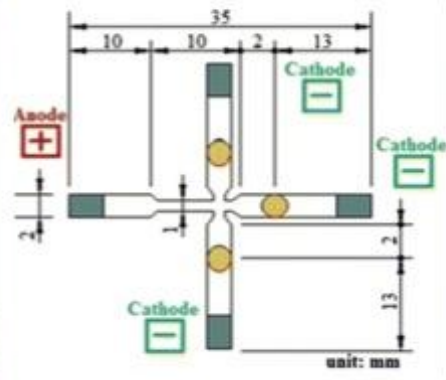

(c)

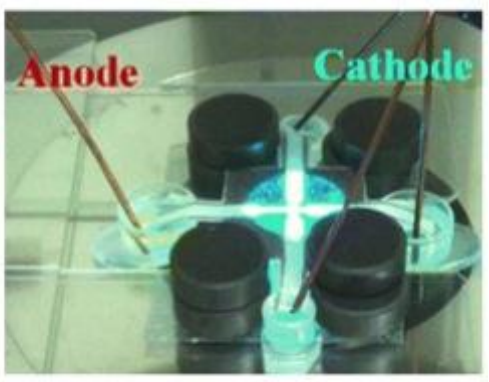

Figure 8: Dimensions and configurations of $\mu$ PADs investigated in present study. (a) Three convergent microchannels with Nafion soaking. The dot lines are defined as centerlines. (b) Schematic illustration of triple-channel $\mu$ PAD. (c) Copper wires and tube lids used as electrodes and reservoirs, respectively. Adopted from [128] with permission.

A low cost rapid prototyping method xurography was used to fabricate microfluidic integrating with nafion membrane by Yuan and co-worker without the need for photolithography [129]. The microchannels were patterned in a double face self-adhesive tape using a cutting plotter, and then were integrated with nafion strip, followed by being sandwiched between two pieces of glass slides. Using this device the fluorescein could be preconcentrated by as high as 5000-fold in $10 \mathrm{~min}$. Han and co-workers integrated the Nafion ${ }^{\mathrm{TM}}$ patterned adhesive tape with a paper-based channel [124]. Different from the normal microfluidic preconcentrators with fixed plug locations, the preconcentrated plug was pulled away from the membrane using an absorbent pad for capillarydriven passive flow. Fluorescent dyes and proteins were continuously preconcentrated achieving high preconcentration performance up to 1000 -fold.

A multilayer micro/nanofluidic device was developed for the selective preconcentration and online collection of different analytes by Choi and co-workers. This device included an ICP layer in which the buffer channel was connected with the main channel through a nafion membrane and analytes were preconcentrated and then separated in this layer, the other layer was a valve layer which was used for selectively collect different analytes. Using this device, a sample mixture of sulforhodamine $B$ and Alexa Fluor 488 could be highly preconcentrated and separated simultaneously, and then be collected using pneumatic microvalves. While this device only showed a 30 -fold preconcentration ratio which was suitable for the low concentration analysis.[130]

One of the main reasons for low sensitivity of ICP is the instability of the preconcentrated plugs. A PDMS microchip integrating with two nafion membranes was used to condense the preconcentrated plugs in a specific location based on merged opposite ICP zones of two nafion membranes, thus 1000-fold enhancement was achieved for proteins. [131]

A conductive polymer, poly(3,4- ethylenedioxythiophene)-polystyrene sulfonate (PEDOT:PSS) was printed onto PDMS microchannels to act as a cation-selective membrane [132]. DNA (25 bases) in 10 $\mathrm{mM}$ phosphate buffered saline was enriched by 1000 -fold in less than $5 \mathrm{~min}$ at an electric field of 75 $\mathrm{V} \mathrm{cm}{ }^{-1}$. Enrichment led to enhanced hybridisation with spots a morpholino microarray printed on the channel floor by 100 -fold. Detection sensitivity was $\sim 1 \mathrm{nM}$ within $15 \mathrm{~min}$. Later, the same group

This article is protected by copyright. All rights reserved. 
modified the device fabrication to enable multiplexing [133]. Up to 5 parallel concentrators were connected to a single inlet/outlet. DNA enrichment was $~ 800$-fold within 15 min with a 10-fold enhancement in the hybridisation speed. The detection limit was $10 \mathrm{nM}$.

A positively charged polymer poly(diallyldimethylammonium chloride) (PDADMAC) was photopolymerised in the glass microchannels, forming the anion-permselective polymer membrane with around $40 \mathrm{~nm}$ pore size, this device was used to selectively preconcentrate the cationic dyes and peptides/proteins.[134]

\section{Elastomeric nanochannels}

Nanochannels can also be made by controlled fracture of PDMS. Kim et al. used an array of shallow nanochannels oriented perpendicular to a single deep microchannel whose width can be adjusted by applying a uniaxial strain [135]. Four layers were assembled to create the device; top PDMS, silicalike hard-PDMS, hard-PDMS, and bottom PDMS. These layers are different in their Young modulus and thickness which determines the depth of the formed cracks. To form the deep channel (micronscale), Sharp reservoirs with a V-notch were designed in the hard-PDMS layer to determine the location of the crack formation when a uniaxial strain (at 15\%) is applied. The shallow nanochannels were created in hard-PDMS after plasma treatment for $600 \mathrm{~s}$ to form a silica-like surface. This layer contained blunt reservoirs and under $6 \%$ strain develops an array of nanochannels. The assembled device was used for DNA capture and linearisation from dilute solutions. The DNA migrates through the microchannel when it is in its open state under an applied electric field of $400 \mathrm{~V} / \mathrm{cm}$. When the strain is released the microchannel closes and traps the DNA in its linearised form (Figure 9). The concentrating effect generated by the nanochannels helped to overcome the entropic costs of concentrating and uncoiling the DNA.

(A)

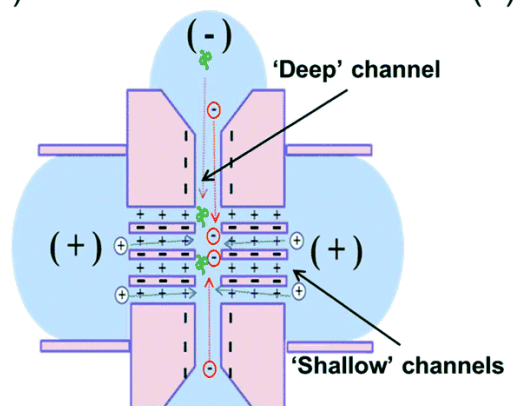

(B)

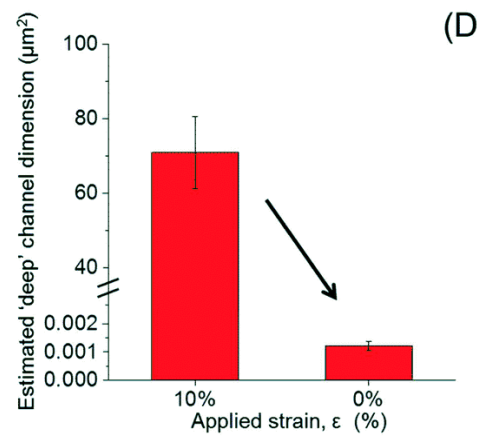

(D) ஃ

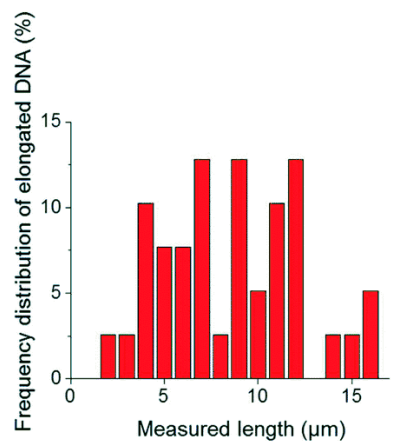

$(-)$

(C)

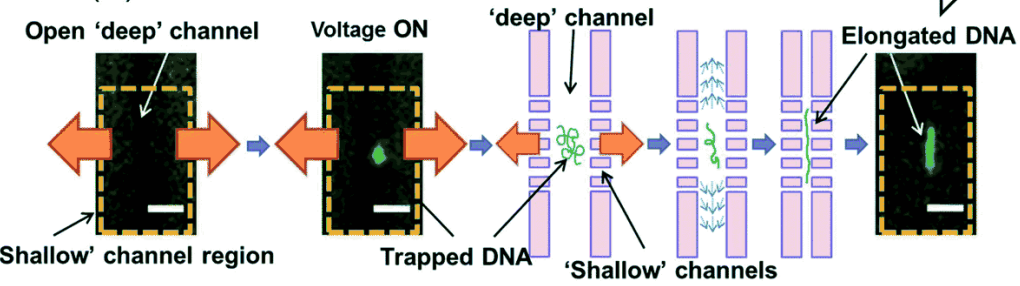

Figure 9: Application of the 'deep' / 'shallow' channel system for capturing and elongating single DNA molecules. (A) A schematic illustrating the ion concentration polarisation and DNA migration generated within the

'deep' / 'shallow' channel junction under an applied electric field. (B) Changes in the cross-sectional dimensions of

This article is protected by copyright. All rights reserved.

Breadmore et al. 
the 'deep' channel in response to a sustained applied strain. (C) An illustration of the multiple steps involved in DNA concentration, trapping, and linearisation in the 'deep' channel. As the 'deep' channel narrows, a hydrodynamic squeezing flow is generated. The coincident application of a hydrodynamic squeezing flow and nano-confinement induces and maintains. DNA elongation. The yellow dashed line represents the 'shallow' nano-scale channel region. The scale bar is $5 \mu \mathrm{m}$. (D) A plot of the frequency distribution of the lengths of elongated $\lambda$-DNA in the closed 'deep' channel. Reproduced from [135] with permission.

A batch process for casting PDMS with nanostructures was reported by Lee et al [136]. A monolithic carbon mold was fabricated by UV photolithography followed by pyrolysis. The mold shrinks by $\sim 90 \%$, which enables creation of nanosized features (710 $\mathrm{nm}$ wide and $32 \mathrm{~nm}$ deep) ready for casting. The nanochannels exhibit a Kingfisher beak shape due to uneven shrinking during pyrolysis. To cast PDMS, a layer of hard-PDMS was first spun and cured followed by another layer of soft PDMS. The hard-PDMS layer will prevent the nanochannels from collapsing. The two layers were then bonded to a glass slide after oxygen plasma treatment. The device was employed for trapping of a single negatively charged microparticle $(1 \mu \mathrm{m})$ under applied electric field. Single entrapment was possible through adjusting the nose length and depth of the Kingfisher' s beak structure next to the nanochannel entrance. Although the microparticle entrapment is size-based exclusion from the nanochannels, the device showed characteristic $\mathrm{i}-\mathrm{V}$ curves and has the potential to be used for concentrating small negatively charged molecules by ICP.

Shallan et al reported a size/mobility trap consisting of two nanojunctions with different pore size created using their previously developed fabrication process of controlled dielectric breakdown [137]. The trap was used for the simultaneous extraction, concentration, and desalting of the antibiotic ampicillin directly from whole blood. Preconcentration was coupled directly with electrophoretic separation within the same device with a total analysis time within $5 \mathrm{~min}$. A linear response was obtained over the range of $2.5-20 \mu \mathrm{g} / \mathrm{mL}$ which is below the therapeutic level of ampicillin [138].

Junction gap breakdown was reported in an irreversibly bond PDMS/glass device as a method for integrating nanochannels [139]. The junction gap connecting two microchannels was $40 \mu \mathrm{m}$ wide. The deposition of gold nanoparticles ( $2 \mathrm{nM}$ solution, $13.7 \pm 0.8 \mathrm{~nm}$ in diameter) at the junction gap before binding PDMS to glass enabled breakdown at much a lower voltage. Applying only $300 \mathrm{~V}$ at the anodic side of the microchannels was enough to achieve nanofractures reliably, compared to $840 \mathrm{~V}$ without the nanoparticles. FITC-labeled BSA in $1 \mathrm{mM}$ PBS was enriched by $1.5 \times 10^{4}$-fold in 60 $\min$. Later, the same group modified the method to alleviate the use of applied voltage for formation of the junction [140]. The nanogap was $50 \mu \mathrm{m}$ wide under which a glass area of $100 \mu \mathrm{m} x$ $700 \mu \mathrm{m}$ was patterned for uniform and homogeneous deposition of the AuNPs layer. Due to EDL overlap, the interstices between the nanoparticles are in the nano-scale. ICP is generated under applied electric field and is affected by AuPNs size. The optimum diameter for AuPNs was found to be $13 \mathrm{~nm}$. FITC-labeled BSA ( $10 \mu \mathrm{M}$ in $10 \mathrm{mM}$ PBS) was enriched by 100 -fold within $30 \mathrm{~min}$. The lower enrichment factor compared with previous work can be attributed to the use of $10 \mathrm{mM}$ PBS instead of the $1 \mathrm{mM}$ buffer.

This article is protected by copyright. All rights reserved. 
Cong et al [141] described another PDMS microfluidic device employing pressure injection for stacking of peptides. The PDMS microchip is comprised of a separation channel, a side channel for sample introduction, and a control channel contained a pneumatic microvalve at the intersection of the separation and sample channels. The closed microvalve serves as a nanochannel preconcentrator under an applied electric potential, enabling the enrichment of peptide samples. After concentration, the valve is opened and the enriched sample is hydrodynamically injected into the separation channel. The microvalve-based method enhanced the detection sensitivity of peptide mixtures by $\sim 450$ fold.

\section{Self-assembled nanoporous media}

Self-assembly is a simple way to fabricate NMI without the need for a clean room access, harmful chemicals, or applying high voltages. Self-assembly of colloidal silica beads ( $300 \mathrm{~nm}$ in diameter) was reported for concentration biomolecules by acting as a cation-selective membrane [142]. The device was fabricated in PDMS comprising 5 microchannels; a sample microchannel in the middle and a bead delivery and buffer microchannels on each side. The pore size of the self-assembled beads is $60 \mathrm{~nm}$ and ICP develops when voltage is applied across the beads. A $10 \mathrm{nM}$ Cy5-tagged DNA in $1 \mathrm{mM}$ phosphate buffer was enriched by $\sim 1700$-fold within $15 \mathrm{~min}$ using $30 \mathrm{~V}$. Also, fluorescent protein B-Phycoerythrin ( $4 \mu \mathrm{g} / \mathrm{mL}$ solution in $1 \mathrm{mM}$ PBS) was enriched by $\sim 100$-fold within $5 \mathrm{~min}$. Although the method is simple, it may not perform efficiently when dealing with biological samples, matrix ionic strength $>100 \mathrm{mM}$.

\section{Extraction}

\section{Solid-phase extraction}

Chromatographic preconcentration via SPE can be used to inject volumes larger than a single capillary - which are often difficult to achieve by stacking and sweeping methods. Hyphenation of SPE can be accomplished in an on-line or in-line manner and with or without the option of automation, with respect to the CE system. An interface (i.e. flow-through vial, tee, valve or crosslike flow-gated interfaces) is needed for on-line mode to transfer the concentrated sample from SPE to the CE system [143]. With in-line SPE-CE, a short SPE column (usually $0.2 \mathrm{~cm}$ to $7.5 \mathrm{~cm}$ in length) can be positioned inside the CE separation capillary. The efforts to integrate SPE with electrophoresis are thriving as evidenced by growing number of reviews on this topic $[5,6,144]$.

\section{In-line SPE-CE}

As the SPE column is placed or synthesised at the inlet of separation capillary, sample loading, washing, elution and separation steps can be carried out in the same capillary without further transfer of eluting solution. No interface is needed, thus this mode is relatively easier and more popular than the on-line mode, but all solutions must pass through the separation capillary which can be both time consuming and may also foul the capillary surface when using complex samples.

This article is protected by copyright. All rights reserved. 


\section{Packed bed column}

The packing of SPE bed inside capillaries resembles the packing procedure of columns for capillary electrochromatography. Tascon et al. [145] developed an in-line packed bed and studied the effect of external high temperature on its performance. They packed a $0.7 \mathrm{~cm}$ long $\times 250 \mu \mathrm{m}$ i.d column with commercially available $\mathrm{C}_{18}$ beads retained with polyethylene frits. The body of the column was coupled to the separation capillary using a sleeve. The effect of temperature $\left(5-90^{\circ} \mathrm{C}\right)$ on $\mathrm{C}_{18}-\mathrm{SPE}-\mathrm{CE}$ was studied on three opioid peptides as model compounds using a home-built mini-thermostatic device that allowed a localised variation of the column temperature via flowing different temperature water. The $\mathrm{S} / \mathrm{N}$ of all peptides increased as the temperature during the loading/cleanup increased up to $60^{\circ} \mathrm{C}$. Preconcentration using column $\mathrm{C}_{18}$ beads at $60^{\circ} \mathrm{C}$ produced method LODs down to $4-7 \mathrm{ng} / \mathrm{mL}$.

Ortiz-Martin et al. [146] evaluated several commercial immobilised metal affinity chromatography (IMAC) sorbents for the analysis of two small peptide fragments of the amyloid $\beta$-protein (A $\beta$ ) (AB(1$15)$ and $A \beta(10-20)$ peptides). Column $(0.7 \mathrm{~cm}$ long $\times 250 \mu \mathrm{m}$ i.d $\times 360 \mu \mathrm{m}$ o.d fused-silica capillary) was inserted at $7.5 \mathrm{~cm}$ from the inlet of the separation capillary using two plastic sleeves with the help of frits. For smaller particle size sorbents (i.e. IMAC POROS ${ }^{\circledR}$ ), frits were placed outside (i.e. in the plastic sleeves) to avoid sorbent bleeding. In the analysis of $A \beta$ peptides, $\mathrm{Ni}(\mathrm{II})$-nitrilotriacetic acid sorbents (HisLink ${ }^{\mathrm{TM}}$ protein purification resin) provided the best results in terms of reproducibility, durability and LODs as compared to two copper metal ion (CU(II)) sorbents based on iminodiacetic acid. A BGE of $25 \mathrm{mM}$ phosphate ( $\mathrm{pH} \mathrm{7.4)}$ and an eluent of $50 \mathrm{mM}$ imidazole (in BGE) yielded a 25 -fold and 5 -fold decrease in the LODs by IMA-SPE-CE-UV for $A \beta(1-15)$ and $A \beta(10-20)$ peptides ( 0.1 and $0.5 \mu \mathrm{g} / \mathrm{mL}$, respectively) with regard to CE-UV ( $2.5 \mu \mathrm{g} / \mathrm{mL}$ for both peptides). The eluent needed to be substituted by a $0.5 \% \mathrm{v} / \mathrm{v}$ acetic acid to be used with MS detection. The method reproducibility values were acceptable (RSD\% < 23.2). Peptide recoveries were rather low $(\sim 15 \%$ comparing the peak areas), which was strongly influenced by the peptide molecular mass (i.e. $A \beta(10-20)$ peptide $(1825.8 \mathrm{Da})$ ) and the sample matrix. To increase the recoveries of the peptides in complex biological samples, they suggested to use an off-line sample pre-treatment, and improve the IMAC sorbent selectivity, capacity and stability.

Preparing frits inside the SPE capillary column can reduce the success rate of the packed column. A fritless approach is frequently opted for ease of construction. The easiest way to create a fritless packed bed is by packing a tube with an i.d. larger than the particles and connect it to capillary with an i.d smaller than the particles. Moreno-Gonzalez et al. [147] used this approach to pack molecularly imprinted polymers sorbents in a large i.d capillary (150 $\mu \mathrm{m}$ and $2 \mathrm{~mm}$ long) and a smaller i.d capillary $(50 \mu \mathrm{m})$. The method was developed in-line with CE-MS of eight regulated veterinary quinolones in bovine milk samples. Up to $22 \mu \mathrm{L}$ of sample ( 2 bar for $15 \mathrm{~min}$ ) could be loaded on the column and the retained analytes were eluted by injecting a plug of methanol/water/ammonia (60/37/3 by volume) for $125 \mathrm{~s}$ at $50 \mathrm{mbar}(60 \mathrm{~nL})$. LOD values down to 1 $\mu \mathrm{g} / \mathrm{kg}$ were obtained, which were at least 30 times lower than the maximum regulatory limit for the quinolones. Using the same sandwich design, Baciu et al. [148] packed an SPE bed with commercially available SPE particles (i.e. $60 \mu \mathrm{m}$ sized OASIS HLB particles) for extraction of cocaine and

This article is protected by copyright. All rights reserved. 
benzoylecgonine. A plug of solvent (methanol) was introduced at $50 \mathrm{mbar}$ for $5 \mathrm{~s}$ and later driven through the SPE sorbent by means of BGE introduced for $250 \mathrm{~s}$. The plug was pushed further by applying pressure for another $250 \mathrm{~s}$. The LODs obtained for hair samples were $0.1 \mathrm{ng} / \mathrm{mg}$ for benzoylecgonine and as low as $0.02 \mathrm{ng} / \mathrm{mg}$ for cocaine, which were low enough to detect these drugs in hair $(0.1-200 \mathrm{ng} / \mathrm{mg})$.

An even simpler way to prepare a packed bed is to use magnetic particles held in place with a magnetic field [148]. Silica coated iron oxide particles were used for the preconcentration of drugs of abuse. To retain the SPE particles inside the capillary, magnets were placed with spacing of $1 \mathrm{~mm}$ around the capillary using a Plexiglas holder (Figure 10B). The holder containing the magnets was set at a distance of $10 \mathrm{~cm}$ from the inlet end of the capillary. After injecting aqueous suspension of the particles at for 5 mins, a dense plug was formed inside the capillary where the magnets were placed (Figure 10C). A new particle bed was generated inside the capillary after each analysis run by applying high pressure (12 bar) without taking the magnets out of the CE cassette. Cocaine, codeine, methadone and morphine were concentrated by loading at $100 \mathrm{mbar}$ for $30 \mathrm{~min}$ and eluted with methanol at 50 mbar for $20 \mathrm{~s}$. This strategy resulted in enrichment factors of $125-700$-fold.

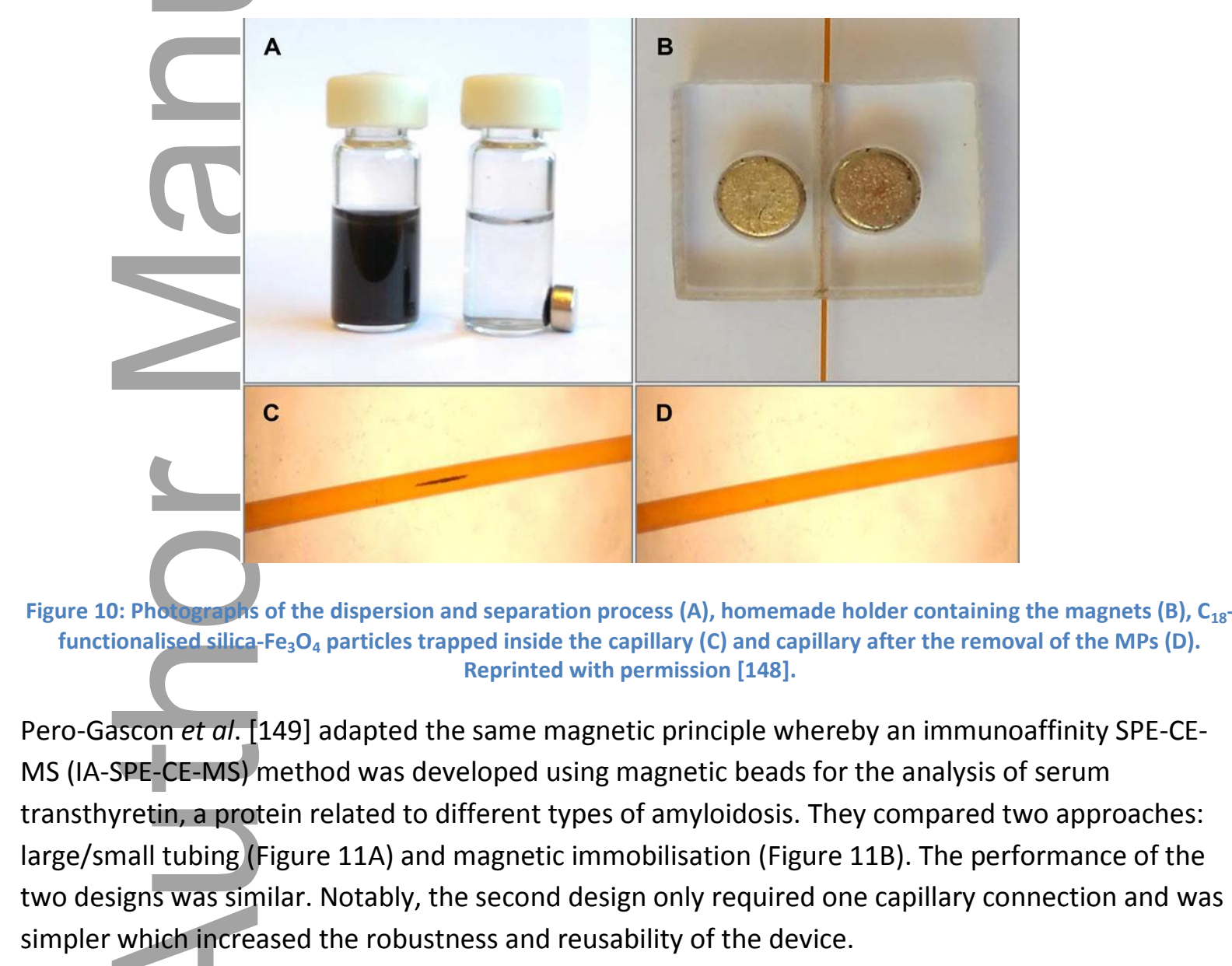

gure 10: Photographs of the dispersion and separation process (A), homemade holder containing the magnets $(B), C_{18^{-}}$ Reprinted with permission [148].

Pero-Gascon et al. [149] adapted the same magnetic principle whereby an immunoaffinity SPE-CEMS (IA-SPE-CE-MS) method was developed using magnetic beads for the analysis of serum transthyretin, a protein related to different types of amyloidosis. They compared two approaches: large/small tubing (Figure 11A) and magnetic immobilisation (Figure 11B). The performance of the two designs was similar. Notably, the second design only required one capillary connection and was simpler which increased the robustness and reusability of the device.

This article is protected by copyright. All rights reserved. 


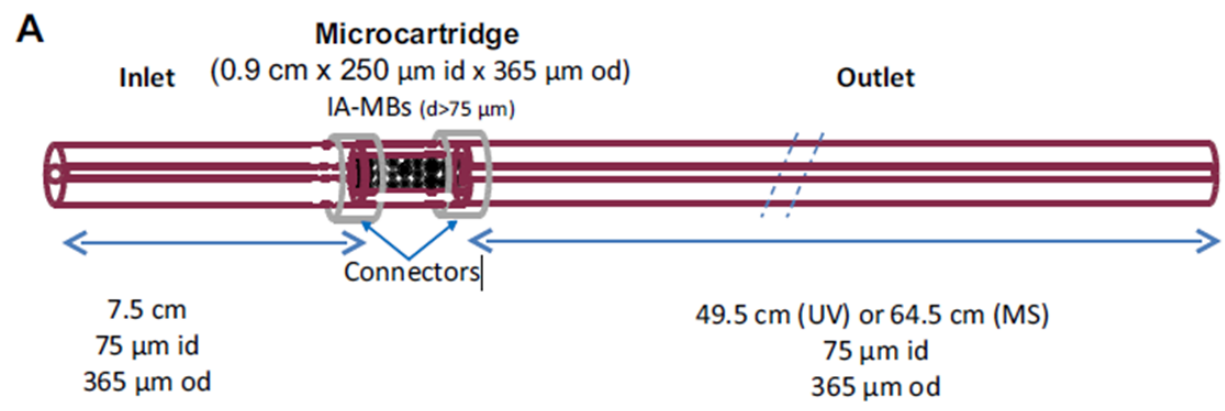

B

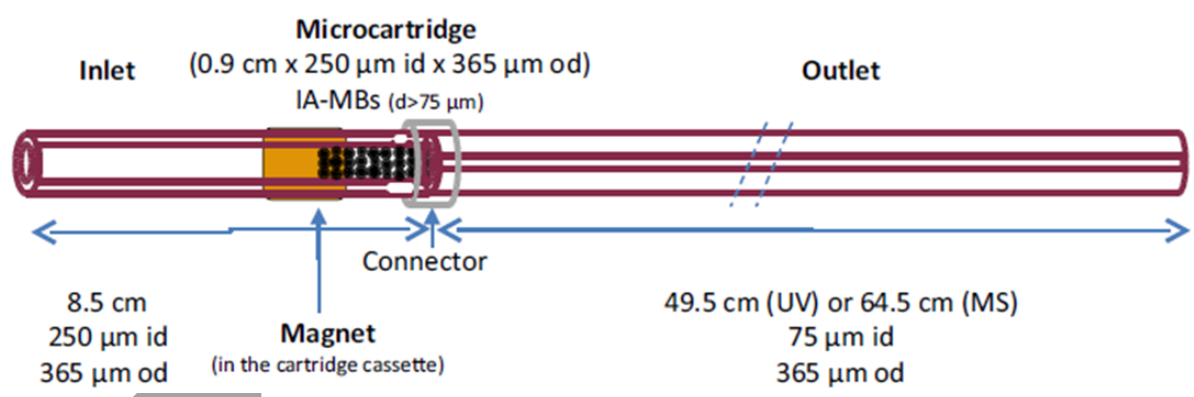

Figure 11: Representations of the column designs; (A) MBs were trapped in a column body of 250 $\mu \mathrm{m}$ i.d due to their particle size and (B) MBs were retained in one of the ends of a piece of $250 \mu \mathrm{m}$ i.d capillary and a magnet prevented the shift and loss of the MBs. Reprinted with permission [149].

\section{Monolithic columns}

The SPE material can also be made directly inside the capillary or microchip, and covalently anchored to the capillary wall eliminating the use of frits and the sandwich design. One drawback to this

This article is protected by copyright. All rights reserved. 
approach is that this requires replacement of the entire capillary once the SPE column has reached the end of its life. Marechal and co-workers prepared a SPE column containing an aptamerphotoclicked silica monolith for in-line enrichment and purification of ochratoxin A [150]. The vinylised monolithic column was grafted with aptamer, with the density could increased by successive grafting layers. With the estimated $5 \mathrm{pM}$ of aptamer, the monolithic SPE was able to capture up to $5 \mathrm{pM}$ of ochratoxin A (about $2000 \mathrm{pg}$ of ochratoxin A). This capacity was sufficient to detect ochratoxin $A$ at the expected in at a concentration below $2 \mathrm{ng} / \mathrm{mL}$. Ochratoxin $A$ was successfully preconcentrated and quantified down to $0.1 \mathrm{pg}$. A quantitative recovery of up to $93 \%$ was achieved in a single elution of $30 \mathrm{pg}$ percolated toxin amount. The reproducibility of the overall process was satisfactory with a $\% \mathrm{RSD}<10 \%$.

Organic-silica hybrid monoliths combine the simplicity and $\mathrm{pH}$ stability of organic monoliths with the mechanical stability and large surface area of silica monoliths. Dovichi and co-workers synthesised a sulfonate-silica hybrid for in-line strong cation exchange-SPE-CE (SCX-SPE-CE) [151]. This method was also coupled with dynamic $\mathrm{pH}$ junction for large volume proteomic analysis by MS. Sample was prepared in an acidic buffer and extracted onto the SCX-SPE monolith and eluted using a basic buffer, while electrophoresis was performed in an acidic buffer. The combination of buffers resulted in formation of a dynamic $\mathrm{pH}$ junction, which further allowed use of relatively large elution buffer volume while maintaining peak efficiency and resolution. By loading $21 \mu \mathrm{L}$ of a $1 \times 10^{-7} \mathrm{M}$ angiotensin II solution, an enrichment factor of 3000 compared to standard electrokinetic injection was achieved on this platform while retaining efficient electrophoretic performance ( $N=44,000$ plates). The LOD was estimated to be at low $\mathrm{pg} / \mathrm{mL}$. The loading capacity of the sulfonate SCX hybrid monolith was $\sim 15$ pmol by frontal analysis with $10^{-5} \mathrm{M}$ angiotensin II. The system was applied to the analysis of bovine serum albumin tryptic digest; the protein coverage was $12 \%$ and 11 peptides were successfully identified. Finally, by loading $5.5 \mathrm{~mL}$ of a $10^{-3} \mathrm{mg} / \mathrm{mL} E$. coli digest, 109 proteins and 271 peptides were identified in just $20 \mathrm{~min}$. To enable identification of more peptides, the same group [152] coupled an in-line monolithic SCX-SPE device to a LPA-coated capillary through a zero dead volume connector. $\mathrm{pH}$ gradient elution was adapted after the preconcentration of E.coli digest. For loading up to $50 \mathrm{ng}$ of $E$.coli digest, they reported that most of the protein groups $(>91 \%)$ and peptides (>85\%), corresponding to 799 protein groups and 3381 peptides could be identified by MS during five $\mathrm{pH}$ bumps with $30 \mathrm{mM}$ elution buffer (ammonium bicarbonate). The improved numbers of peptide and protein identifications can be attributed to the efficient fractionation by the $\mathrm{pH}$ gradient elution, which decreased the complexity of the sample in each elution step and improved the signal intensity of low abundance peptides.

Nordman et al. [153] implemented a porous polymer monoliths-based SPE in an SU-8 microchip with an on-chip ESI emitter and a coaxial sheath liquid channel for coupling to MS. In contrast to other typically synthesised monoliths in chips, they used a high-power UV laser for maskless photopolymerisation of a precisely defined, cross shaped porous polymer monolith at the injection cross of the SU-8 separation chip. The four-step protocol for operation of the fully integrated SPEMCE-ESI chip (Figure 12) is: (1) sample loading, (2) rinsing (of unretained, hydrophilic impurities), (3) injection (release of retained hydrophobic analytes), and (4) elution followed by separation and MS

This article is protected by copyright. All rights reserved. 
detection. As a result, 15- to 23-fold enrichment factors (using tramadol and propranolol) were obtained at loading time as short as $25 \mathrm{~s}$ without sacrificing the throughput of the electrophoretic analysis. The performance of the chip was repeatable within $3.1 \%$ and $11.5 \%$ RSD in terms of migration time and peak height, respectively, and linear correlation was observed between the loading time and peak area.

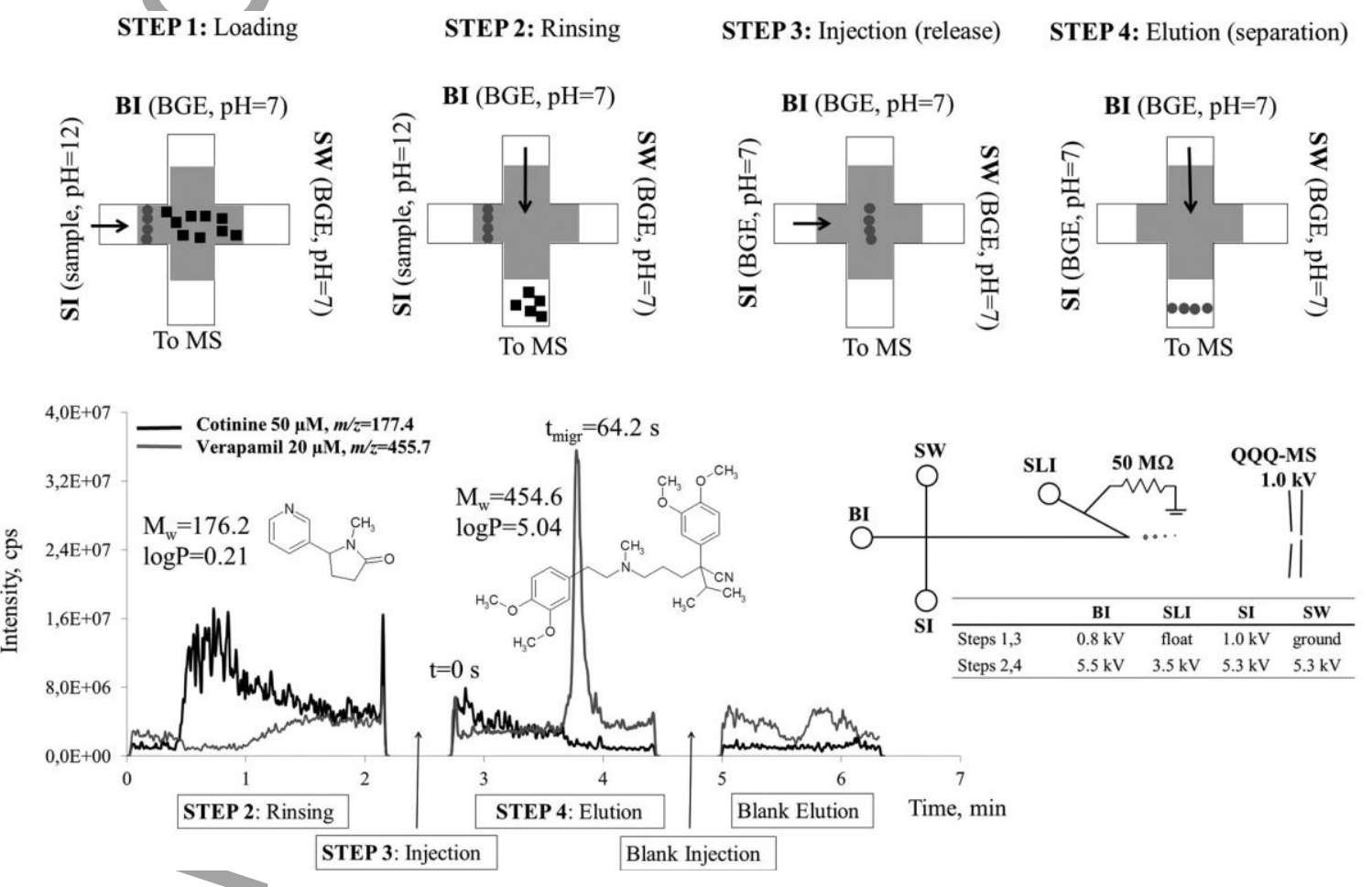

Figure 12: The operation principle of the SPE-ME-ESI microchip was illustrated with squares and circles representing hydrophilic and hydrophobic sample components, respectively. EIE of the $[\mathrm{M}+\mathrm{H}]^{+}$ions of cotinine (black line, $\left.50 \mu \mathrm{M}\right)$ and verapamil (grey line, $20 \mu \mathrm{M}$ ) show that the hydrophilic, unretained cotinine was washed away in step 2, whereas hydrophobic verapamil was selectively retained (steps 1-2), released (step 3), and eluted to MS (step 4). The electric field strength during separation was $800 \mathrm{~V} / \mathrm{cm}$ and other operating voltages (steps 1-4) were according to the schematic view. The blank injection ( 4.5-5 $\mathrm{min}$ ) and elution ( 5-6.5 $\mathrm{min}$ ) in the end of the electropherogram showed no memory effect; all sample components were efficiently released from the monolith in steps 3-4. The sample components were loaded in 2\% ammonium hydroxide solution ( $\mathrm{pH} 12$ ) and the BGE was $30 \mathrm{mM}$ ammonium acetate with $50 \%$ methanol. Reprinted with permission [153].

Wooley and co-workers developed an a multilayer microfluidic device consisting of a pneumatic peristaltic pump and fluid control valves and a porous polymer monolith for SPE and a microchannel for electrophoresis [154]. The porous polymer monolith column (acrylate-based monolith with $C_{8}$ functional groups) was synthesised using UV photopolymerisation. Fluidic and control channel dimensions were optimised to actuate valves with $30 \mathrm{psi}$ and produce reasonable flow rates. The preconcentration capability of the SPE unit was demonstrated through MCE of ferritin and two model peptides (phenylalanine-alanine and glycine-glycine-tyrosine-arginine) in the integrated system. Phenylalanine-alanine, glycine-glycine-tyrosine-arginine and ferritin were preconcentrated $4-, 12$ - and 50 -fold, respectively (Figure 13). The loading capacity of the polymer monolith was $56 \mathrm{fM}$ (25 ng) for ferritin.

This article is protected by copyright. All rights reserved. 

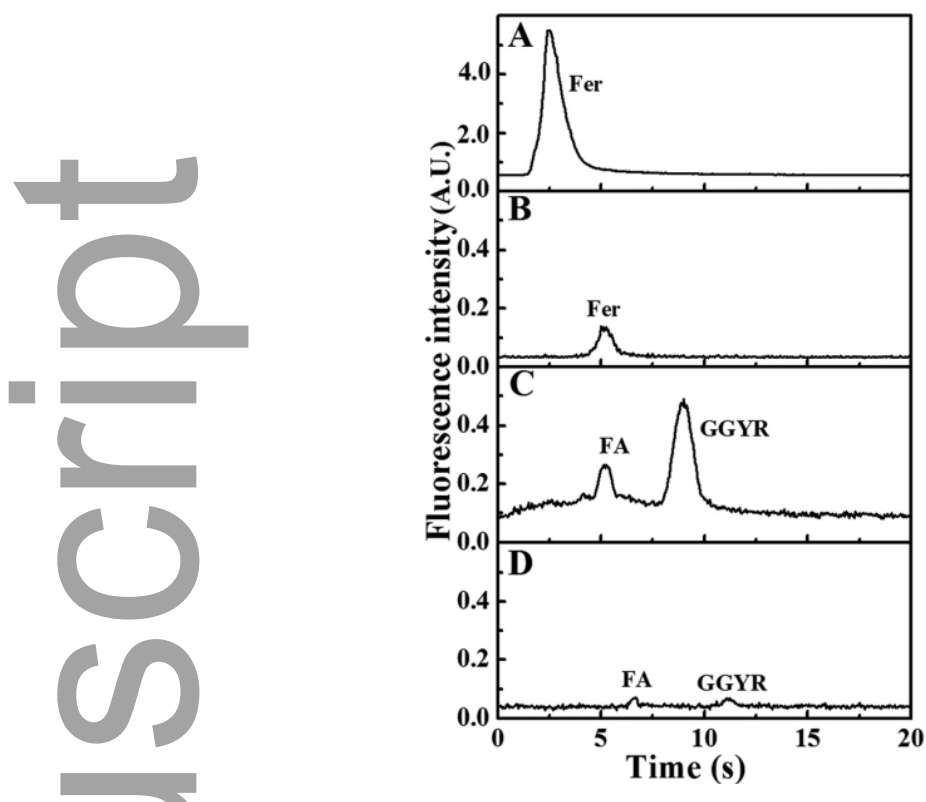

Figure 13: Microchip electropherograms showing the effects of on-chip sample enrichment. (A) Electrophoretic separation of fluorescein isothiocyanate-ferritin $(100 \mathrm{nM})$ with enrichment on a $\mathrm{C}_{8}$ monolith and (B) without enrichment $(C)$ Electrophoretic separation of a mixture of two labelled peptides, phenylalanine-alanine and glycineglycine-tyrosine-arginine (both $500 \mathrm{nM}$ ), with enrichment on a $\mathrm{C}_{8}$ monolith and (D) without enrichment. The $y$-axis range in (A) was 10x greater than in (B-D). Reprinted with permission [154].

Other approach for SPE integration

Zhang et al. [155] prepared an in-column SPE device by coating a BPA imprinted MIP material directly in the separation capillary using LED-induced polymerisation. The preparation of the MIP with ACN improved its extraction ability compared to when toluene or methanol was used as the polymerisation solvent. The primary driving forces behind the rebinding process,

(hydrophobic interaction and hydrogen bonding) were strongly related to the $\mathrm{pH}$ of the sample; the extraction efficiency was optimum at pH 7.0. The combination of MIP-SPE with CE produced a linear relationship between the CE peak areas versus the BPA concentration in the range from 3 to $300 \mathrm{ng} / \mathrm{mL}$ with LOD as low as $0.8 \mathrm{ng} / \mathrm{mL}$; the LOD was over 100 -fold lower than that of direct CE determination.

\section{On-line SPE-CE}

Unlike in-line SPE-CE, on-line SPE has the column coupled to the CE system in an automated way, typically via an interface with flow-switching ability. Weng et al. developed a new sheath flow gating interface for the on-line coupling of SPE column (containing hydroxylated poly(glycidyl methacrylateco-ethylene dimethacrylate) monolith) with CE-UV [156]. The sheath flow design was based on the flow gating principle, and thus achieves small void volumes $(10 \mathrm{~nL})$. In order to evaluate the stability of the injection through the interface, 100 consecutive injections of phenol solution were conducted over a nearly $3.5 \mathrm{~h}$ period by delivering the solution to the interface through a section of $50 \mu \mathrm{m}$ i.d. capillary. The precisions of the injections were determined to be $2.43 \%, 3.86 \%$, and $4.25 \%$ for peak height, peak area and migration time, respectively. The RSD values were much better than those obtained using other previous interfaces [157-161], which was attributed to no dilution and

This article is protected by copyright. All rights reserved. 
dispersion of the sample during the injections and to it being automated. However the \%RSDs were slightly poorer than those obtained by Jorgenson's group [162] using a transverse flow gating interface, which might be due to the poor data acquisition system in the present work. The preconcentration factors of phenols were up to 530-fold. When applied to the on-line SPE-CE-UV of phenols in river water, the recoveries samples spiked at three different levels were in the range of 93.6-102.8\% with the RSD\% ranging from 2.0 to $4.5 \%$, demonstrating that the sheath flow interface could reproducibly transfer $\mathrm{nL}$ of fractions from SPE onto CE.

\section{Liquid-liquid extraction}

LLE can be regarded as the most commonly used sample pretreatment technique for matrix elimination and/or analyte preconcentration. In the past decade, a range of advanced miniaturised LLE methods were proposed aimed to reduce the amount of solvent consumed, as well as to deal with very small volumes of sample. In addition, high enrichment factors could be easily obtained in these approaches by simply utilising an acceptor phase of very small volume. Hence, with the likelihood of achieving a volume of acceptor extract in microlitre or even down to nanolitre range, the in- and on-line coupling of miniaturised LLE methods with CE, with or without a membrane as phase barrier, has seen an increasing level of attention.

The direct coupling of single-drop microextraction (SDME) with CE was first introduced by Choi et al. in 2009 [163]. In general, SDME can be performed using two different approaches: a two-phase or a three-phase system. In the earlier approach, a single drop of an organic solvent at the capillary inlet tip end is used as the acceptor phase. The acceptor phase is then placed into the aqueous sample, and the targeted analytes are extracted into the organic droplet based on passive diffusion. In the three-phase approach, a thin layer of organic phase is used to separate the aqueous acceptor droplet hanging at the inlet of the capillary from the aqueous sample solution. The targeted analytes are extracted to the acceptor phase through the organic layer based on their acidic/basic dissociation equilibrium. Kim et al. demonstrated the feasibility of in-line coupling of two-phase SDME with CE-MS to analyse selected basic drugs in spiked human urine [164]. The authors successfully overcame the problem of lacking outlet reservoir in a conventional CE-MS system by simply placing a temporary outlet vial containing the run buffer at the ESI tip to provide a reverse flow of the acceptor phase during drop formation and extraction. The in-line SDME-CE-MS/MS technique resulted in 130-150-fold enrichment with $10 \mathrm{~min}$ of extraction. The proposed approach was able to perform effective sample clean-up and prevent isobaric interference from the urine matrix. Springer and Lista described an in-line coupling of SDME in a three-phase design with CE for the determination of fluoroquinolones in surface and groundwater samples [165]. Enrichment factors of 6- and 40-fold and detection limits of $10.1 \mathrm{ng} / \mathrm{mL}$ and $55.3 \mathrm{ng} / \mathrm{mL}$ were achieved for the targeted ciprofloxacin and enrofloxacin, respectively. García-Vázquez et al. demonstrated a similar approach to determine nonsteroidal anti-inflammatory drugs (NSAIDs) in urine samples based on the use of a three-phase SDME coupled in-line to CE with UV detection [166]. The developed approach was successfully applied to the analysis of human urine samples with detection limits ranging between 1.0 and $2.5 \mu \mathrm{g} / \mathrm{mL}$ and enrichment factors in the range of 14- to 44 -fold for all of the targeted NSAIDs.

This article is protected by copyright. All rights reserved. 
Lee et al. demonstrated a novel and simple in-tube microextraction (ITME) using the liquid inside the capillary inlet tip end as an acceptor phase, without forming a drop at the capillary tip as in SDME [167]. The approach has been combined with headspace extraction and applied to the analysis of selected chlorophenols present in red wine samples. A schematic of in-line headspace-ITME in a commercial CE instrument is shown in Figure 16. Entire procedures, including HS extraction, preinjection of extract, waiting and CE separation and detection, were carried out automatically using built-in programs of a commercial CE instrument. This method has the potential to be further expanded into a direct immersion-ITME-CE for liquid phase microextraction.

Another interesting approach, termed as liquid extraction surface analysis (LESA), was recently introduced by Sung et al. as a new alternative surface-sampling technique [168]. Organophosphorus pesticides on the external surface of an apple fruit were directly extracted into a liquid microjunction formed by dispensing the extractant from the inlet tip of a separation capillary. After extraction, the analytes were derivatised 'in-capillary' and analysed with CE. A schematic of the LESA-CE system is shown in Figure 14. One of the major advantages of this approach is that quantitative analysis can be performed in a convenient manner without dilution of the target analytes on a solid surface during bulk sample preparation. The practicability of the LESA-CE system is believed to be promising for the analysis of biological surfaces of cells and tissues or even thermal surfaces.

(1) HS extraction

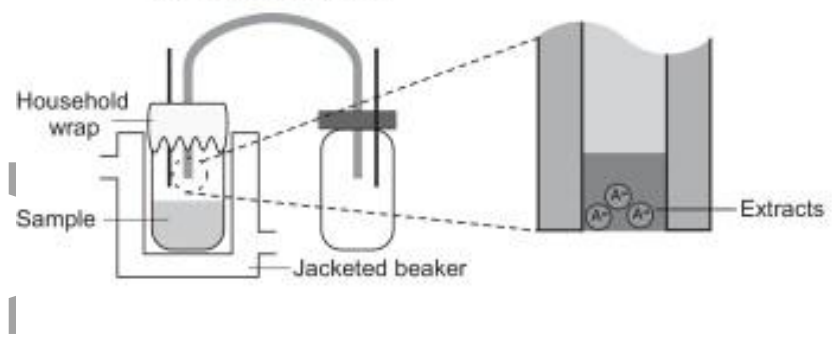

(3) Waiting

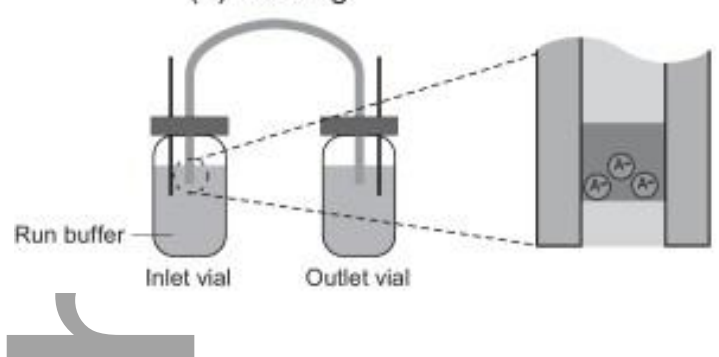

(2) Pre-injection

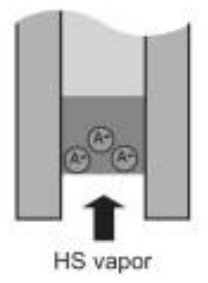

(4) Electrophoresis

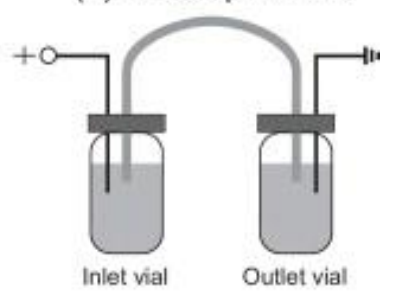

Figure 14:HS-ITME procedures: (1) HS extraction, (2) pre-injection, (3) waiting, and (4) electrophoresis. Reproduced from [167] with permission.

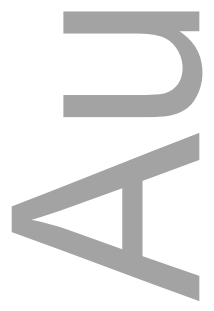

This article is protected by copyright. All rights reserved. 


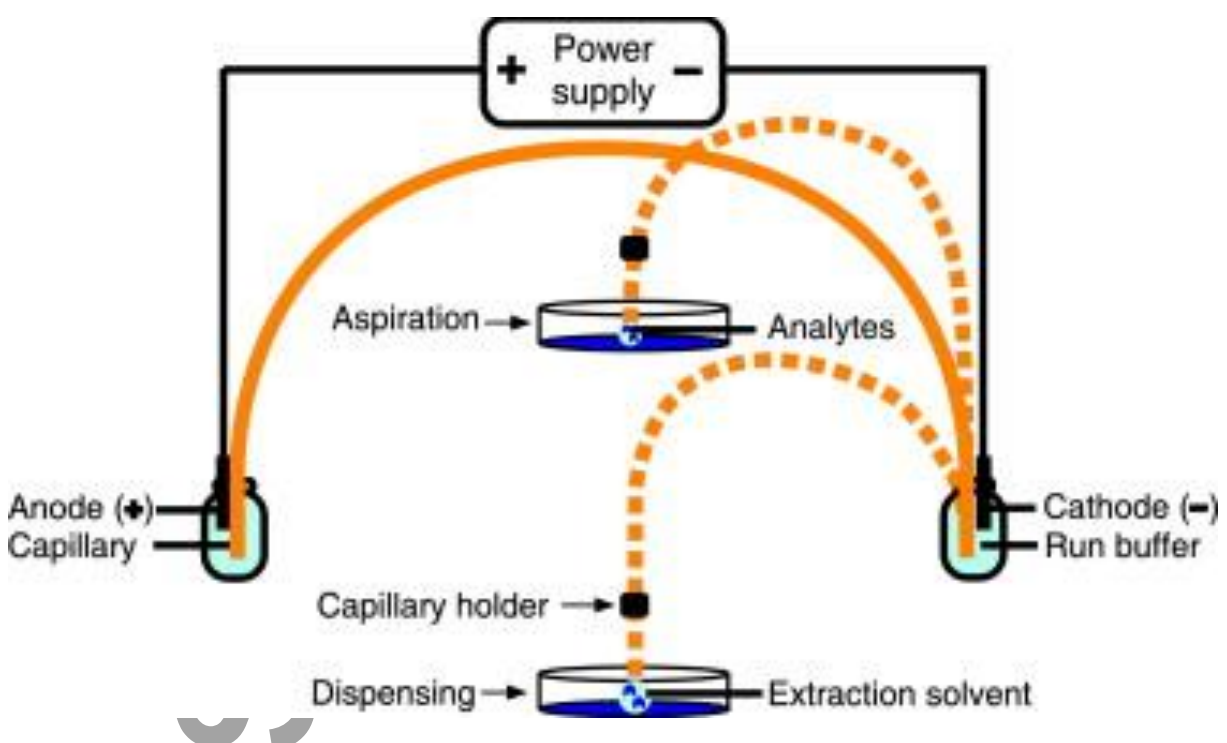

Figure 15: Scheme for LESA-CE. Dashed lines represent the extraction cycle of dispensing and aspiration steps. LESA: extraction solvent of $10 \mathrm{mM}$ sodium tetraborate buffer of $\mathrm{pH} 8.75$; injection of $350 \mathrm{~nL}$ extraction solvent; dispensing of $330 \mathrm{~nL}$; aspiration of $340 \mathrm{~nL}$; repeat of dispensing/aspiration cycles. Reproduced from [168] with permission.

On-line coupling of supported liquid membrane (SLM) extractions to CE was previously introduced by Kubáň et al., which enabled efficient sample cleanup and direct CE injections of samples after extraction [169]. Recently, the same research group re-examined the existing SLM-CE method and proposed a new on-line SLM-CE approach by coupling extraction across SLM a large electrokinetic injection, IITP preconcentration and CZE separation of the extracted analytes, which aimed to enhance the detection sensitivity. In principle, a long plug of a low conductivity extract obtained from SLM extraction is electrokinetically injected into the separation capillary. Targeted analytes present in the injected extract are temporarily stacked and preconcentrated at the sharp IITP boundary and subsequently separated as narrow zones by CZE. The proposed approached was applied to the analysis of selected basic drugs in spiked human urine and serum samples. Analytical sensitivity was found to increase up to 340 times compared with SLM extraction coupled on-line to CZE with standard hydrodynamic injections.

\section{Sequential stacking methods}

The in-capillary combination of two or more stacking techniques performed as steps is referred to as sequential stacking. The motivation of sequential stacking is to further enhance the analyte detection sensitivity. In some cases, two stacking mechanisms occurred simultaneously and this form is termed as synergistic stacking.

\section{Field amplified stacking - sweeping/MSS}

Field amplified stacking is ideal to combine with MSS/Sweeping because the mechanisms are entirely different. These combinations enable longer sample injections than by FASI or FASS alone because of the focusing of the overloaded sample injection by MSS or sweeping. There were 6, 1,

This article is protected by copyright. All rights reserved. 
and 4 paper(s) on FASI -sweeping [40, 170-174], FASS-sweeping [175], and FASI-MSS [176-179], respectively. In addition, 2 reports applied the combination of FASI-sweeping-MSS in a three-step stacking approach [180, 181].

A common FASI-sweeping strategy for cationic analytes is to use SDS as pseudo-phase, low pH separation electrolyte (to suppress the EOF), low conductivity acidic sample diluent, and uncoated fused-silica capillary. For anionic analytes, a typical strategy involves cetyltrimethyl ammonium bromide (CTAB) as pseudo-phase, alkaline separation electrolyte, low conductivity alkaline sample diluent, and a coated capillary to suppress or reverse the EOF (anodic EOF).

In FASI-sweeping, the cationic analytes were propranolol enantiomers [174], homocysteine thiolactone [171], $\beta$-blockers [30,32], and the heavy metals $\mathrm{Pb}(\mathrm{II}), \mathrm{Cu}(\mathrm{II}), \mathrm{Hg}(\mathrm{II}), \mathrm{Zn}(\mathrm{II})$, and $\mathrm{Co}(\mathrm{II})$ [172]. The anionic metabolites uroporphyrin and coproporphyrin were also studied [170]. The samples included human saliva, blood, and urine, and environmental waters. However, the analysis of real samples by FASI required a low conductivity sample which was obtained for the biological samples by protein precipitation and/or LLE following drying and reconstitution [171, 173, 174] and for the environmental waters after filtration to remove particulate matter [172]. Sweeping of the cations was performed using SDS micelles except for the determination of the complexed heavy metals with 4-(2-pyridylazo)resorcinol where polyamidoamine dendrimers were used. The pseudophase for the anionic analytes was di-n-butyl L-tartrate-boric acid. All the reports involved UV detection at 195-527 nm. FASI was performed for 20-250 s with applied voltages of 5 to $15 \mathrm{kV}$.

In FASS-sweeping, negatively-charged enrofloxacin and ciprofloxacin were determined using UV detection at $270 \mathrm{~nm}$ in counter-EOF MEKC [175]. The samples were milk, milk powder, chicken muscle, swine muscle, liver, and kidney. Sample preparation was performed by homogenisation of the solid samples prior to LLE. Sodium deoxycholate was used as the pseudo-phase. In order to improve the affinity of the analyte to the bile salt, and thus improve the detection sensitivity, $5 \mathrm{mM}$ $\mathrm{\gamma}$-cyclodextrin was used as sample modifier. A long hydrodynamic injection for $300 \mathrm{~s}$ enabled enhancements for enrofloxacin and ciprofloxacin of 376 and 406, respectively. The LODs were 1.87 and $2.21 \mathrm{ng} / \mathrm{mL}$, correspondingly.

In FASI-MSS, cationic chlorpheniramine enantiomers [178] and quaternary ammonium herbicides [176] as well as anionic penicillins [179] and sulfonamides [177, 179] were studied. The samples were milk, purified, river, and sea water. The sample preparation included evaporation and reconstitution [177], SPE [179], and cloud point extraction [176]. The latter was a simple and fast clean-up for polar analytes, where the supernatant after centrifugation was directly applicable for FASI. The detection of the analytes was by UV (200 and $254 \mathrm{~nm}$ ) and MS. An advantage of using MSS with MS is that the non-volatile pseudo-phase moves away from the detector and thus detector contamination is avoided. The analysis of anions, however, required capillary coating which was achieved by successive multiple ionic polymer layers using hexadimethrine bromide and poly(sodium-4-styrenesulfonate). The pseudo-phases were CTAB and ammonium lauryl sulfate or SDS for the negatively-charged and positively-charged analytes, respectively. The enantiomeric separation of chlorpheniramine also required the use of the chiral pseudo-phase 2 -hydroxpropyl- $\beta$ -

This article is protected by copyright. All rights reserved. 
cyclodextrin. FASI was performed for $90-180 \mathrm{~s}$ at 10 to $15 \mathrm{kV}$ which provided an enhancement of 563328. The sample diluent was non-buffered or slightly buffered (2-2.5 mM electrolyte) solution containing a high concentration of organic solvent (e.g., 40-60\% acetonitrile or methanol) which was made alkaline for anions or acidic for cations. The LODs were $0.002-9 \mathrm{ng} / \mathrm{mL}$.

In order to obtain high enrichment factors in FASI, the sample must be prepared in a very dilute electrolyte or water. This provides high field strengths during sample injection. The presence of salts in real samples especially those from biological origin therefore requires desalting prior to FASI. In order to extend the application of FASI to samples that meet the minimum requirement of field amplification (the sample is only $10 \mathrm{x}$ less conductive compared to the separation electrolyte), the three-step combination of FASI or FESI, sweeping, and MSS has been developed. Figure 16 shows the schematic of the novel FASI-sweeping-MSS which - performed in three distinct steps - to analyse six cationic drugs and four anionic antibiotics from pig plasma [180, 181]. Sample preparation was LLE, followed by drying and reconstitution of extracted sample in $10 \mathrm{mM}$ phosphoric acid or $1.5 \mathrm{mM}$ ammonium acetate. The three-step procedure was performed by first FASI of the low conductivity sample into the capillary filled with high conductivity separation electrolyte (devoid of pseudo-phase), second electrokinetic injection of the pseudo-phase for sweeping, and third hydrodynamic injection of aqueous organic solvent to induce MSS. After FASI, the micelles swept the long zone of oppositely migrating FASI stacked analytes. The micelle-bound analytes then were released at the organic solvent rich zone or MSS boundary. The CZE separation finally occurred when all the micelles migrated through the solvent rich zone. For the anions, coating of the capillary with poly(diallyldimethylammonium chloride) was performed to create an anodic EOF. FASI was $420 \mathrm{~s}$ at $10 \mathrm{kV}$ and $60 \mathrm{~s}$ at $-10 \mathrm{kV}$ for the cationic and anionic analytes, respectively. The pseudo-phases were $10 \mathrm{mM}$ SDS and $15 \mathrm{mM} \mathrm{CTAB}$, correspondingly. The reversal of the analytes effective electrophoretic mobility in the MSS step was achieved by hydrodynamic injection of a short plug of $30 \%$ acetonitrile or $60 \%$ methanol. The obtained enhancement for the cationic neostigmine, dibucaine, diphenhydramine, imipramine, propranolol, and verapamil were 3088-6499 which enabled sensitive detections with LODs of 10-40 ng/mL. The enhancement and LODs for anionic penicillin $\mathrm{G}$, oxacillin, ampicillin, and amoxicillin, were 519-954 and 6.6-13.2 ng/mL, respectively. The three-step stacking afforded 6 to 161 times lower LODs when compared to FASI alone.

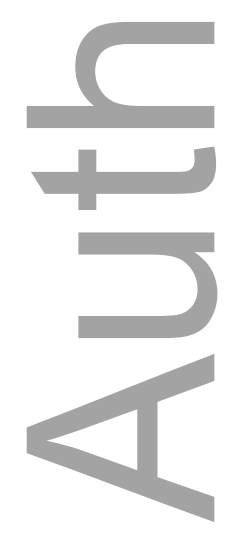

This article is protected by copyright. All rights reserved. 


\section{A1 FESI}

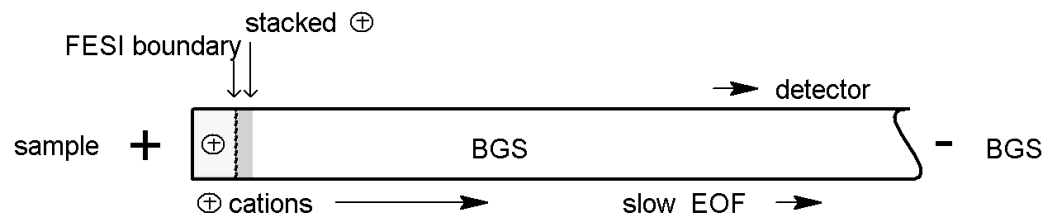

\section{A2 Long FESI}

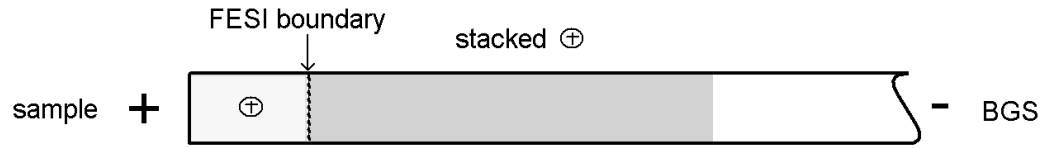

\section{B1 Sweeping}

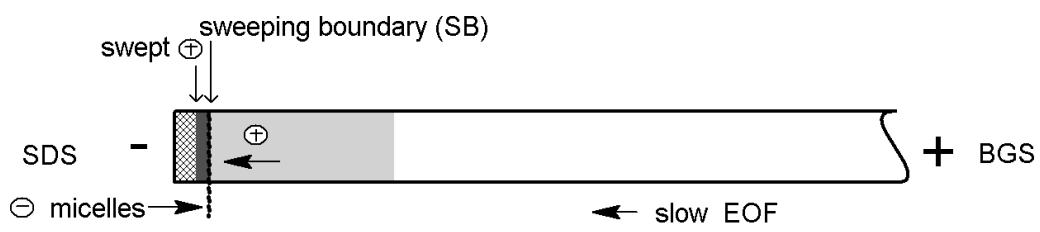

B2 End of the sweeping
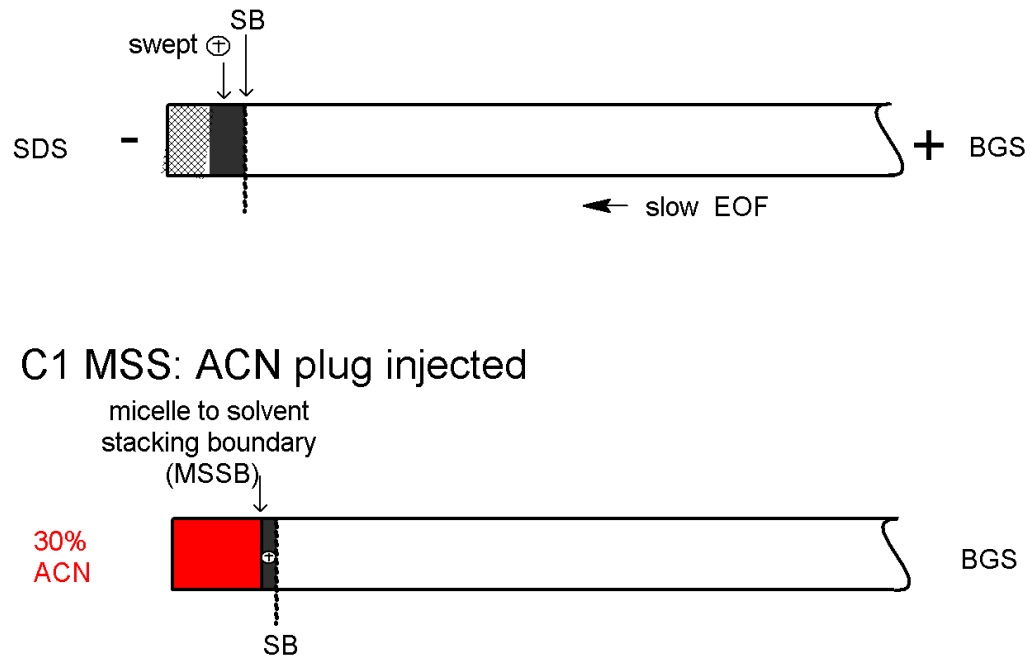

C2 MSS: voltage applied

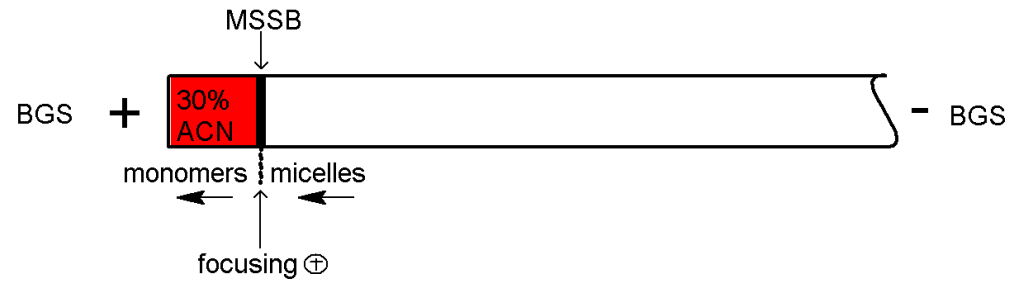

This article is protected by copyright. All rights reserved. 
Figure 16: Three-step stacking approach by FESI, sweeping and MSS in CZE of cationic drugs. (A1) The fused-silica capillary was conditioned with low-pH BGS. The sample solution was introduced by FESI at positive polarity. (A2) Long FESI produced broad zone of stacked cationic analytes. The slow EOF towards the outlet vial introduced the sample diluent. (B1) The start of the sweeping step was replacement at the sample solution by the low-pH electrolyte with SDS micelles. The application of voltage at negative polarity caused the migration of the micelles into capillary. The slow EOF towards the inlet vial removed the low conductivity sample diluent injected in FESI. (B2) The analytes were swept at the front of micelles sweeping boundary (SB). (C1) MSS was by injection of short plug of $30 \%$ ACN. The MSS boundary (MSSB) was found between swept cationic analytes and organic solvent rich zones. (C2) Application of voltage at positive polarity caused migration of negatively charged micelles which transported the cationic analytes to the MSSB. The effective electrophoretic velocity of the micelle bound cationic analytes was to the anode. At the MSSB, the micelles collapsed and released the analytes, the effective electrophoretic velocity of the cationic analytes reversed to the direction of the cathode. The MSS step ended when all the micelles passed through the MSSB.

\section{Sweeping - MSS}

Sweeping-MSS is performed by the injection of micellar solution with micelles having opposite charge to the target analytes, sample solution devoid of micelles and organic solvent, and finally organic solvent solution. The micelles sweep the analytes in the sample zone and then transport the swept analytes to the organic solvent rich zone where the analytes are refocused by MSS and separate by zone electrophoresis.

During this review period there were four papers on sweeping-MSS [182-185]. All articles investigated cationic analytes including quaternary ammonium herbicides [182], nitroimidazole drugs [183], and strychnosand quinolizidine alkaloids [184, 185]. The samples were beer, rabbit plasma, and Chinese herbal medicines. The sample preparations included protein precipitation [183], reflux extraction [184, 185], and simultaneous electrophoretic concentration and separation (SECS) [182]. SECS was a simple (no need for drying and reconstitution of the extracted sample) and purely electric field driven off-line sample preparation which was based on the well-known on-line sample concentration technique of FASI or electrokinetic injection in CE $[186,187]$. Fused-silica capillaries and UV-detection (200-275 nm) were applied. SDS served as the micellar solution for sweeping and MSS. Interestingly, there was no report on the analysis of anionic analytes. The separation electrolyte contained no organic solvent [182] or $0.5-40 \%$ methanol [183-185]. For the former, an organic solvent solution was injected after the sample to induce MSS. The MSS boundary was between the organic solvent plug and the sample. When the separation electrolyte contained organic solvent, the boundary was between sample and separation electrolyte. The samples were injected by pressures of 35 or 50 mbar for 90 to $150 \mathrm{~s}$ which resulted in enhancement of 12 to 52 . The LODs were $2.3-30 \mathrm{ng} / \mathrm{mL}$.

\section{dynamic pH junction - sweeping}

Dynamic pH junction can be combined with sweeping by preparing the sample in pseudo-phase-free solution with a $\mathrm{pH}$ value different than the separation electrolyte containing the pseudo-phase. The sample is introduced by pressure for a long time. The difference in the $\mathrm{pH}$ of the two solutions causes a change in the analytes electrophoretic mobility which leads to the stacking. Sweeping occurs after the analytes are stacked by dynamic $\mathrm{pH}$ junction. This combination is only applicable for analytes where the electrophoretic mobility significantly changes depending on the $\mathrm{pH}$ environment.

This article is protected by copyright. All rights reserved. 
In dynamic pH junction-sweeping [188-193], the analytes included drugs[188], neurotransmitters [190], nucleosides [189], amino acids [191], and food and cosmetic preservatives [192, 193]. The samples were pharmaceutical formulations, food and beverages, and human serum and urine. The sample preparations included homogenisation and dilution of the food and beverage samples [188, 192], protein precipitation [190,191] and further SPE treatment [189] of the biological samples. Detection of the analytes was performed using direct UV or indirect detection at wavelengths of 200-257 nm. For sweeping, the separation electrolytes contained negatively charged SDS, borate, or $\beta$-cyclodextrin as the pseudo-phase. For dynamic $\mathrm{pH}$-junction, the samples were prepared in acidic or neutral solutions, so that the analytes were not or incompletely ionised. The separation electrolytes were basic which assured complete ionisation of most of the studied analytes. In one report, a basic and low conductivity sample was injected into a capillary conditioned with a slightly lower $\mathrm{pH}$ than the separation electrolyte ( $\mathrm{pH} 8.2)$. In this case, the analyte were ionised in the sample and then neutralised in the separation electrolyte before sweeping. This form of stacking is reminiscent of reversed dynamic $\mathrm{pH}$-junction $[82,194]$. The injected sample plugs ranged from $3.2-$ $58.7 \%$ to the detection window which translated to enhancements of 8-930. The LODs were 0.68$1100 \mathrm{ng} / \mathrm{mL}$.

\section{Electrokinetic supercharging}

Electrokinetic supercharging (EKS) is the named coined by the Hirokawa group to refocus analytes by IITP after a FASI injection $[195,196]$. The technique is capable of providing more improvements in detection sensitivity than either ITP or FASI solely can achieve. Since long EKI is utilised during the FASI step, the movement of the stacking boundary is usually unavoidable. This boundary movement could be detrimental to the performance of the EKS system. There have been several reports over the past decade aimed to enhancing the performance of EKS via manipulation of EOF or hydrodynamic pressure for the control of boundary movement [197-202]. Breadmore and coworkers [59] reinvestigated the application of a hydrodynamic counterflow in order to immobilize the stacking boundary for enrichment of bacterial cells. After filling the capillary with the LE $(50 \mathrm{mM}$ Tris- $\mathrm{HCl}, \mathrm{pH} 8.0$ with $0.5 \% \mathrm{w} / \mathrm{v}$ of PVP), the counter pressure was employed during EKI of the sample. Applying a counter pressure $(8,963 \mathrm{~Pa})$, the authors were able to inject the bacterial cells suspended in the TE ( 5 mM Tris-HEPES, pH 7.8) for $6 \mathrm{~min}$ at $-12 \mathrm{kV}$. The method improved the sensitivity by a factor of 4 when compared to EKS without a counterflow and provided an LOD of E. Coli down to 78 cells $/ \mathrm{mL}$ which represents the lowest concentration LOD for bacterial cell analysis by CE.

In EKS, the switch from the stacking to the separation mode usually takes place in CZE. Recently, Wang et al [203] exploited EKS for preconcentration of biogenic amines in C57BL/6 mice brain in MEKC mode. The authors employed $50 \mathrm{mM} \mathrm{LiCl}$ as a LE and $100 \mathrm{mM}$ TEA as a TE and the running buffer was $\mathrm{NaH}_{2} \mathrm{PO}_{4}, \mathrm{pH}$ 5.0. The authors noticed that even in the CZE mode, the stacking takes place, however, baseline resolution was not accomplished for the three analytes (dopamine, epinephrine and nor-epinephrine). However, the presence of $10 \mathrm{mM}$ Tween-20 in the BGE provided successful MEKC condition for separation and baseline resolution of the stacked analytes. The tissue extract of model mice brain was treated with TFA $(0.01 \% \mathrm{w} / \mathrm{v})$ in order to ensure that the analytes are positively charged and was injected at $15 \mathrm{kV}$ for $180 \mathrm{~s}$. The method provided LOD down to 0.42

This article is protected by copyright. All rights reserved. 
$\mathrm{ng} / \mathrm{mL}$ and the separation was performed in $<10 \mathrm{~min}$. In another EKS/MEKC report, Lin et al [204] described an augmentation of EKS and sweeping for preconcentration of phenolic acids in fruit juices. The system employs a BGE (120 $\left.\mathrm{mM} \mathrm{NaH}_{2} \mathrm{PO}_{4}, \mathrm{pH} 2.0\right)$ of which phosphate ion acts as a LE. The sample was dissolved in borate buffer $\mathrm{pH} 8.0$ and the borate ion acted as the TE. During EKI of the sample, the negatively charged analytes enter the capillary by their own electrophoretic mobility since the EOF is suppressed by the low-pH BGE. In the meantime, a pH junction was produced between the sample matrix and the background electrolyte. Accordingly, a zone with less conductivity was created because of the neutralisation reaction at the boundary. Owing to the different dissociation states in both adjoining electrolytes, the mobility levels of the analytes gradually decreased when entering the capillary. Additionally, mobility differences between the borate and phosphate ions created the transient ITP state. After injection of the sample, an acidic immobilisation buffer was placed at the two ends of the capillary. The immobilisation buffer has the same composition of the BGE with the addition of 175 mM SDS. Upon application of the separation voltage, the anionic micelles entered the capillary and further accumulate the analytes into a narrow band by the action of sweeping. The separation was further proceeded in the MEKC mode as shown in the schematic of the system in Figure 17. The technique provided 25,000 fold enhancement in detection sensitivity and the LODs were down to $10 \mathrm{fg} / \mathrm{mL}$.

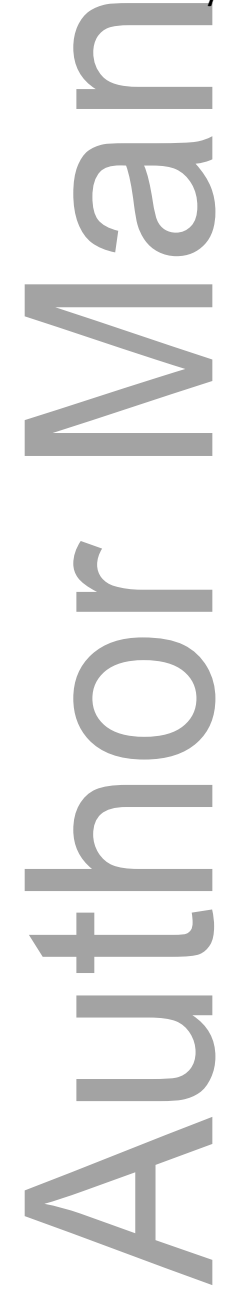

This article is protected by copyright. All rights reserved. 


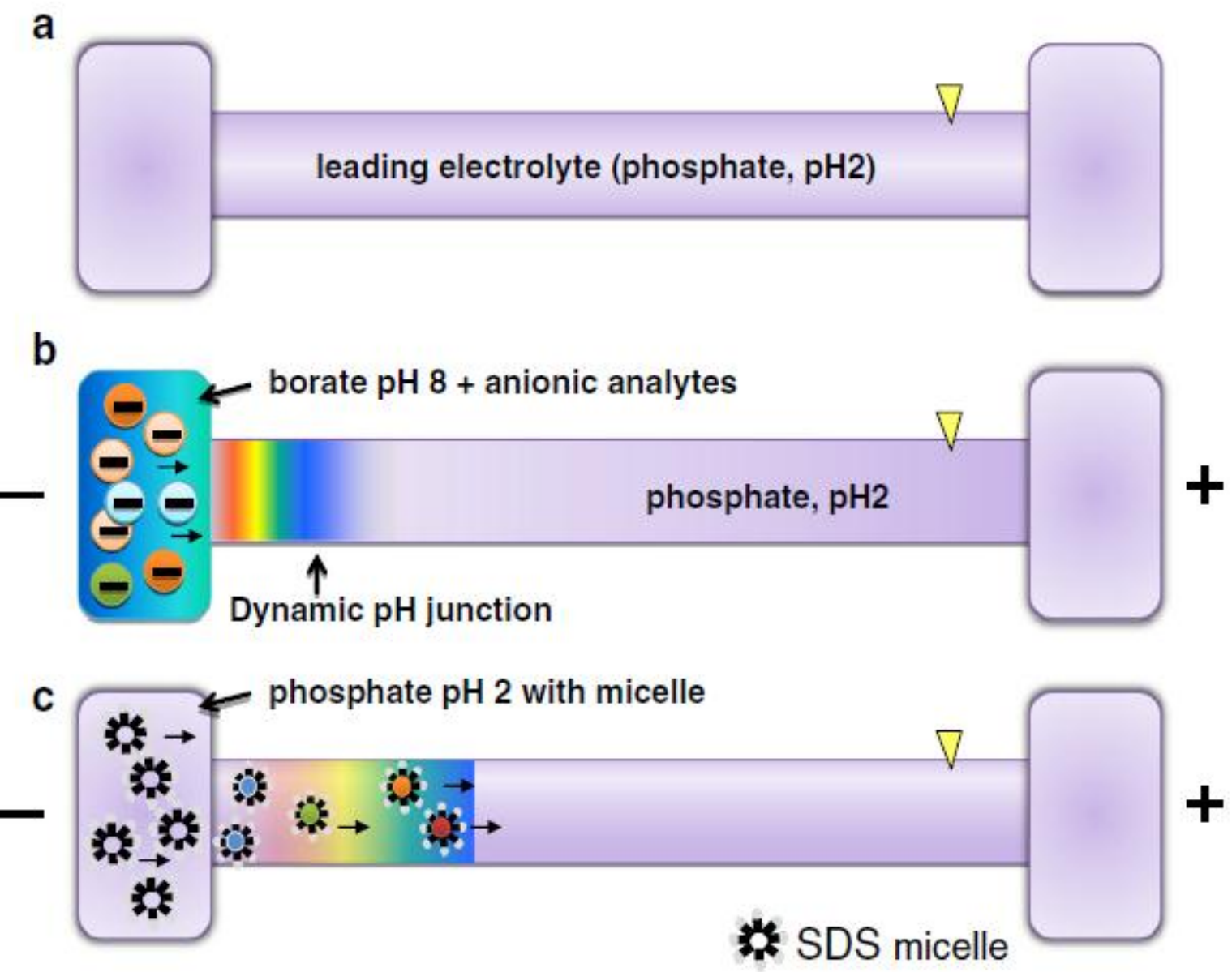

Figure 17: Mechanism of the online focusing by EKS/sweeping. Reproduced from Lin, Y.-H., Huang, H.-C., Hsu, W.-L., Analytical and Bioanalytical Chemistry 2015, 407, 7093-7100. [204] with permission.

In an EKS/CZE system, Lu et al [205] investigated the preconcentration of melamine in dairy products. After filling the capillary with the BGE, the $L E(50 \mathrm{mM} \mathrm{NaCl})$ was introduced into the capillary by hydrodynamic injection at 0.5 psi for $24 \mathrm{~s}$; then, the sample was injected electrokinetically by a positive voltage $(10 \mathrm{kV})$ for $100 \mathrm{~s}$, followed by a small volume of the terminator ( $50 \mathrm{mM}$ tetrabutylammonium bromide) which was hydrodynamically injected at $0.5 \mathrm{psi}$ for $18 \mathrm{~s}$. A voltage of $+25 \mathrm{kV}$ was applied for both the online focusing and the separation of the analytes. The authors reported an enhancement factor of 2285 and the LOD was $0.7 \mathrm{ng} / \mathrm{mL}$.

\section{Concluding remarks}

The last few years have seen approximately 150 papers published in the field of on-line and in-line concentration in both capillaries and microchips. The older techniques have transitioned from fundamental understanding through to routine application, while new approaches are still being developed to be more powerful, more selective, and more applicable to untreated samples. It is

This article is protected by copyright. All rights reserved. 
unlikely that there will be any significant changes in this trend over the next few years, but there is becoming more and more approaches that can be used to achieve the desired outcome for almost any specified application.

\section{Acknowledgments}

The Australian Research Council is thanked for funding and provision of a Future Fellowship to MCB (FT130100101) and a Future Fellowship to JPQ (FT100100213). HHS thanks the Swiss National Science Foundation (Advanced Mobility Grant P300P2_147771), and the Ministry of Higher Education Malaysia (MOHE) for financial support through a Research University Grant (Q.J130000.2426.03G30). MD thanks the support of the Postdoctoral Translational Scholars Program (PTSP) of MICHR (UL1TR000433)

\section{References}

[1] Breadmore, M. C., J. Chromatogr. A 2012, 1221, 42-55.

[2] Breadmore, M. C., Electrophoresis 2007, 28, 254-281.

[3] Breadmore, M. C., Thabano, J. R. E., Dawod, M., Kazarian, A. A., Quirino, J. P., Guijt, R. M., Electrophoresis 2009, 30, 230-248.

[4] Breadmore, M. C., Dawod, M., Quirino, J. P., Electrophoresis 2011, 32, 127-148.

[5] Breadmore, M. C., Shallan, A. I., Rabanes, H. R., Gstoettenmayr, D., Abdul Keyon, A. S., Gaspar, A., Dawod, M., Quirino, J. P., Electrophoresis 2013, 34, 29-54.

[6] Breadmore, M. C., Tubaon, R. M., Shallan, A. I., Phung, S. C., Abdul Keyon, A. S., Gstoettenmayr, D., Prapatpong, P., Alhusban, A. A., Ranjbar, L., See, H. H., Dawod, M., Quirino, J. P., Electrophoresis 2015, 36, 36-61.

[7] Malá, Z., Křivánková, L., Gebauer, P., Boček, P., Electrophoresis 2007, 28, 243-253.

[8] Malá, Z., Šlampová, A., Gebauer, P., Boček, P., Electrophoresis 2009, 30, 215-229.

[9] Aranas, A. T., Guidote Jr, A. M., Quirino, J. P., Anal. Bioanal. Chem. 2009, 394, 175-185.

[10] Malá, Z., Gebauer, P., Boček, P., Electrophoresis 2011, 32, 116-126.

[11] Kazarian, A. A., Hilder, E. F., Breadmore, M. C., J. Sep. Sci. 2011, 34, $2800-2821$.

[12] Šlampová, A., Malá, Z., Pantůčková, P., Gebauer, P., Boček, P., Electrophoresis 2013, 34, 3-18.

[13] Ross, D., Locascio, L. E., Anal. Chem. 2002, 74, 2556-2564.

[14] Meighan, M. M., Staton, S. J., Hayes, M. A., Electrophoresis 2009, 30, 852-865.

[15] Ramautar, R., Somsen, G. W., de Jong, G. J., Electrophoresis 2014, 35, 128-137.

[16] Ramautar, R., Somsen, G. W., De Jong, G. J., Electrophoresis 2010, 31, 44-54.

[17] Giordano, B. C., Burgi, D. S., Hart, S. J., Terray, A., Anal. Chim. Acta 2012, 718, 11-24.

[18] Wen, Y., Li, J., Ma, J., Chen, L., Electrophoresis 2012, 33, 2933-2952.

[19] Sánchez-Hernández, L., Castro-Puyana, M., Marina, M. L., Crego, A. L., Electrophoresis 2012, 33, 228-242.

[20] Kitagawa, F., Otsuka, K., J. Chromatogr. A 2014, 1335, 43-60.

[21] Chiu, T. C., Anal. Bioanal. Chem. 2013, 405, 7919-7930.

[22] Chen, Y., Lü, W., Chen, X., Teng, M., Cent. Eur. J. Chem. 2012, 10, 611-638.

[23] Breadmore, M. C., Sänger-Van De Griend, C. E., LCGC North America 2014, 32, 174-186.

This article is protected by copyright. All rights reserved. 
[24] Breadmore, M. C., Bioanalysis 2015, 7, 3053-3055.

[25] Burgi, D. S., Chien, R. L., Anal. Chem. 1991, 63, 2042-2047.

[26] Chien, R. L., Burgi, D. S., Anal. Chem. 1992, 64, 1046-1050.

[27] Tu, Y.-Y., Hsieh, M.-M., Chang, S. Y., Electrophoresis 2015, 36, 2828-2836.

[28] Sahore, V., Kumar, S., Rogers, C. I., Jensen, J. K., Sonker, M., Woolley, A. T., Anal. Bioanal. Chem. 2016, 408, 599-607.

[29] Chien, R. L., Burgi, D. S., J. Chromatogr. 1991, 559, 141-152.

[30] D'Ulivo, L., Feng, Y.-L., Electrophoresis 2015, 36, 1024-1027.

[31] Xu, Z., Li, A., Wang, Y., Chen, Z., Hirokawa, T., J. Chromatogr. A 2014, 1355, 284-290.

[32] Wen, J., Zhang, W.-T., Cao, W.-Q., Li, J., Gao, F.-Y., Yang, N., Fan, G.-R., Molecules 2014, 19, 4907-4923.

[33] Zhang, S., Wu, D., Zhu, J., Liu, X., J. Liq. Chrom. Rel. Tech. 2016, 39, 59-64.

[34] van Wijk, A. M., Niederlander, H. A. G., van Ogten, M. D., de Jong, G. J., Anal. Chim. Acta 2015, 874, 75-83.

[35] Yang, L., Zhou, S., Xiao, Y., Tang, Y., Xie, T., Food Chem. 2015, 188, 446-451.

[36] Guo, L., Wang, Y., Zheng, Y., Huang, Z., Cheng, Y., Ye, J., Chu, Q., Huang, D., J. Chromatogr. B 2016, 1014, 70-74.

[37] Lian, D.-S., Zhao, S.-J., J. Chromatogr. B 2015, 978, 29-42.

[38] Chen, Z., Zhang, L., Lu, Q., Ye, Q., Zhang, L., Electrophoresis 2015, 36, $2720-2726$.

[39] Kitagawa, S., Buno, H., Sakabe, K., Nakagawa, H., Ohtani, H., J. Sep. Sci. 2014, 37, 3181-3187.

[40] Gstoettenmayr, D., Quirino, J., Ivory, C. F., Breadmore, M., J. Chromatogr. A 2015, 1408, 236242.

[41] Lee, S.-Y., Mueller, C. E., Electrophoresis 2014, 35, 855-863.

[42] Ysabel Pinero, M., Jurado, N., Bauza, R., Arce, L., Valcarcel, M., Revista Cientifica-Facultad De Ciencias Veterinarias 2014, 24, 55-63.

[43] Sajida Paryeen, Memon, S. Q., Siyal, A. N., Memon, N., Khuhawar, M. Y., Food. Anal. Meth. 2016, 1-9.

[44] Shao, Y.-X., Chen, G.-H., Fang, R., Zhang, L., Yi, L.-X., Meng, H.-L., J. Agi. Food. Chem. 2016, 64, 3456-3461.

[45] Zhao, Y., Wang, D., Li, X., Liu, Y., Chemistry International 2016, 2, 121-127.

[46] Yu, L., Lin, S., Sha, M., Sun, Z., Xu, H., Wang, L., Xu, W., Chen, Z., Chen, G., Anal. Methods. 2015, 7, 9489-9494.

[47] Wang, N., Su, M., Liang, S., Sun, H., Food. Anal. Meth. 2016, 9, 1020-1028.

[48] Chen, C., Li, X., Xie, X., Chang, F., Li, M., Zhu, Z., Anal. Methods. 2016, 8, 4272-4276.

[49] Tuma, P., J. Chromatogr. A 2016, 1447, 148-154.

[50] Liu, J., Tian, J., Li, J., Azietaku, J. T., Zhang, B.-1., Gao, X.-m., Chang, Y.-X., Electrophoresis 2016, 00,1-8.

[51] Polikarpov, N., Potolytsyna, V., Bessonova, E., Tripp, S., Appelhans, D., Voit, B., Kartsova, L., J. Chromatogr. A 2015, 1378, 65-73.

[52] Buzatto, A. Z., Guedes, S. F., Silva, M. d. O., Gallafrio, J. M., Colnaghi Simionato, A. V., Electrophoresis 2015, 36, 2968-2975.

[53] Oukacine, F., Taverna, M., Anal. Chem. 2014, 86, 3317-3322.

[54] Liu, B., Cong, Y., Ivory, C. F., J Sep Sci 2014, 37, 2395-2402.

This article is protected by copyright. All rights reserved. 
[55] Wegman, D. W., Ghasemi, F., Khorshidi, A., Yang, B. B., Liu, S. K., Yousef, G. M., Krylov, S. N., Anal. Chem. 2015, 87, 1404-1410.

[56] Wegman, D. W., Ghasemi, F., Stasheuski, A. S., Khorshidi, A., Yang, B. B., Liu, S. K., Yousef, G. M., Krylov, S. N., Anal. Chem. 2016, 88, 2472-2477.

[57] Dziubakiewicz, E., Buszewski, B., Electrophoresis 2014, 35, 1160-1164.

[58] Sautrey, G., Duval, R. E., Chevalley, A., Fontanay, S., Clarot, I., Electrophoresis 2015, 36, 26302633.

[59] Phung, S. C., Nai, Y. H., Macka, M., Powell, S. M., Guijt, R. M., Breadmore, M. C., Anal Bioanal Chem 2015, 407, 6995-7002.

[60] Gebauer, P., Mala, Z., Bocek, P., Electrophoresis 2014, 35, 746-754.

[61] Mala, Z., Gebauer, P., Bocek, P., Anal Chim Acta 2016, 907, 1-6.

[62] Piestansky, J., Marakova, K., Koval, M., Mikus, P., J Chromatogr A 2014, 1358, 285-292.

[63] Piestansky, J., Marakova, K., Veizerova, L., Galba, J., Mikus, P., Anal Chim Acta 2014, 826, 8493.

[64] Kler, P. A., Huhn, C., Anal Bioanal Chem 2014, 406, 7163-7174.

[65] Abdul Keyon, A. S., Guijt, R. M., Bolch, C. J., Breadmore, M. C., J Chromatogr A 2014, 1364, 295-302.

[66] Hattori, T., Fukushi, K., Electrophoresis 2016, 37, 267-273.

[67] Malá, Z., Gebauer, P., Boček, P., Electrophoresis 2015, 36, 2-14.

[68] Castro, E. R., Manz, A., J. Chromatogr. A 2015, 1382, 66-85.

[69] Tetala, K. K. R., Vijayalakshmi, M. A., Anal. Chim. Acta 2016, 906, 7-21.

[70] Han, C. M., Katilius, E., Santiago, J. G., Lab Chip 2014, 14, 2958-2967.

[71] Qu, Y., Marshall, L. A., Santiago, J. G., Anal. Chem. 2014, 86, 7264-7268.

[72] Vilensky, R., Bercovici, M., Segal, E., Adv. Funct. Mater. 2015, 25, 6725-6732.

[73] Kuriyama, K., Shintaku, H., Santiago, J. G., Electrophoresis 2015, 36, 1658-1662.

[74] Schwartz, O., Bercovici, M., Anal. Chem. 2014, 86, 10106-10113.

[75] Gerver, R. E., Herr, A. E., Anal. Chem. 2014, 86, 10625-10632.

[76] Khnouf, R., Goet, G., Baier, T., Hardt, S., Analyst 2014, 139, 4564-4571.

[77] Adkins, J., Boehle, K., Henry, C., Electrophoresis 2015, 36, 1811-1824.

[78] Wu, C. Y., Adeyiga, O., Lin, J., Di Carlo, D., Lab Chip 2014, 14, 3258-3261.

[79] Rosenfeld, T., Bercovici, M., Lab Chip 2014, 14, 4465-4474.

[80] Li, X., Luo, L., Crooks, R. M., Lab Chip 2015, 15, 4090-4098.

[81] Aebersold, R., Morrison, H. D., Journal of Chromatography 1990, 516, 79-88.

[82] Britz-McKibbin, P., Bebault, G. M., Chen, D. D. Y., Anal. Chem. 2000, 72, 1729-1735.

[83] Fan, Y., Li, S., Fan, L., Cao, C., Talanta 2012, 95, 42-49.

[84] Yang, Q., Fan, L. Y., Huang, S. S., Zhang, W., Cao, C. X., Electrophoresis 2011, 32, 1015-1024.

[85] Wang, L., MacDonald, D., Huang, X., Chen, D. D. Y., Electrophoresis 2016, 37, 1143-1150.

[86] Ludwig, K. R., Sun, L., Zhu, G., Dovichi, N. J., Hummon, A. B., Anal. Chem. 2015, 87, 95329537.

[87] Zhu, G., Sun, L., Yan, X., Dovichi, N. J., Anal. Chem. 2014, 86, 6331-6336.

[88] Zhu, G., Sun, L., Heidbrink-Thompson, J., Kuntumalla, S., Lin, H. Y. U., Larkin, C. J.,

McGivney, J. B., Dovichi, N. J., Electrophoresis 2016, 37, 616-622.

[89] Umeda, H., Kitagawa, S., Ohtani, H., Anal. Sci. 2015, 31, 1151-1154.

[90] Terabe, S., Otsuka, K., Kunimichi, I., Akihiro, T., Ando, T., Anal. Chem. 1984, 56, 111-113.

This article is protected by copyright. All rights reserved. 
[91] Quirino, J. P., Terabe, S., Science 1998, 282, 465-468.

[92] Quirino, J. P., Haddad, P. R., Anal. Chem. 2008, 80, 6824-6829.

[93] Guidote, A. M., Quirino, J. P., J. Chromatogr. A 2010, 1217, 6290-6295.

[94] Quirino, J. P., J. Chromatogr. A 2009, 1216, 294-299.

[95] Abd El-Hady, D., Albishri, H. M., Rengarajan, R., Wätzig, H., Electrophoresis 2014, 35, 19561964.

[96] Fang, R., Chen, G. H., Yi, L. X., Shao, Y. X., Zhang, L., Cai, Q. H., Xiao, J., Food Chem. 2014, $145,41-48$

[97] Hernández-Mesa, M., García-Campaña, A. M., Cruces-Blanco, C., Food Chem. 2014, 145, 161 167.

[98] Kubalczyk, P., Borowczyk, K., Chwatko, G., Głowacki, R., Electrophoresis 2015, 36, 10281032.

[99] Liu, H.-Y., Hwang, T.-J., Tsai, I. L., Kuo, C.-H., Electrophoresis 2015, 36, 534-542.

[100] Sun, J., He, H., Liu, S., J. Sep. Sci. 2014, 37, 1679-1686.

[101] Tsai, I. C., Su, C.-Y., Hu, C.-C., Chiu, T.-C., Anal. Methods 2014, 6, 7615-7620.

[102] Wuethrich, A., Haddad, P. R., Quirino, J. P., J. Chromatogr. A 2015, 1401, 84-88.

[103] Yue, M. E., Li, Q., Xu, J., Jiang, T. F., Food. Anal. Meth. 2015, 699-705.

[104] Ying Rang Hizuru Nakajima, S. K. K. U. H. Z., J. Sep. Sci. 2015, 38, 2722-2728.

[105] Abd El-Hady, D., Albishri, H. M., Food Chem. 2015, 188, 551-558.

[106] Abd El-Hady, D., Albishri, H. M., Talanta 2015, 139, 150-158.

[107] Hsiao, W. Y., Jiang, S. J., Feng, C. H., Wang, S. W., Chen, Y. L., J. Chromatogr. A 2015, 1383, 175-181.

[108] Kukusamude, C., Srijaranai, S., Quirino, J. P., Anal. Chem. 2014, 86, 3159-3166.

[109] Lin, Y.-H., Lu, C.-Y., Jiang, S.-J., Hsiao, W.-Y., Cheng, H.-L., Chen, Y.-L., Electrophoresis 2015, 36, 2396-2403.

[110] Chao, H.-C., Liao, H.-W., Kuo, C.-H., J. Chromatogr. A 2016, 1445, 149-157.

[111] Kukusamude, C., Srijaranai, S., Quirino, J. P., Electrophoresis 2014, 35, 1478-1483.

[112] Thang, L. Y., See, H. H., Quirino, J. P., Electrophoresis 2016, 37, 1166-1169.

[113] Yang, X., Liu, S., Wang, C., Wang, Z., Anal. Methods. 2014, 6, 8640-8644.

[114] Quirino, J. P., Aranas, A. T., Electrophoresis 2012, 33, 2167-2175.

[115] Pei-Shan, C., Yu-Jui, F., Horn-Jiunn, S., Wei-Cheng, T., Lab Chip 2015, 15, 319-330.

[116] Yeh, L.-H., Hughes, C., Zeng, Z., Qian, S., Anal. Chem. 2014, 86, 2681-2686.

[117] Aïzel, K., Fouillet, Y., Pudda, C., J. Nanoparticle. Res. 2014, 16, 1-9.

[118] Rosentsvit, L., Wang, W., Schiffbauer, J., Chang, H.-C., Yossifon, G., J. Chem. Phys. 2015, $143,224706$.

[119] Wang, C., Shi, Y., Wang, J., Pang, J., Xia, X.-H., ACS App. Mater. Interface. 2015, 7, 68356841.

[120] Yoon, J., Cho, Y., Han, S., Lim, C. S., Lee, J. H., Chung, S., Lab Chip 2014, 14, 2778-2782.

[121] Dinh-Tuan, P., Shaegh, S. A. M., Yang, C., Nam-Trung, N., Sens. Actuators B 2016, 222, 735740.

[122] Gong, M. M., Nosrati, R., San Gabriel, M. C., Zini, A., Sinton, D., J.A.C.S. 2015, 137, 1391313919.

[123] Gong, M. M., Zhang, P., MacDonald, B. D., Sinton, D., Anal. Chem. 2014, 86, 8090-8097.

[124] Han, S. I., Hwang, K. S., Kwak, R., Lee, J., Lab Chip 2016.

This article is protected by copyright. All rights reserved. 
[125] Hong, S., Kwak, R., Kim, W., Anal. Chem. 2016, 88, 1682-1687.

[126] Yang, R.-J., Pu, H.-H., Wang, H.-L., Biomicrofluidics 2015, 9, 014122.

[127] Yeh, S.-H., Chou, K.-H., Yang, R.-J., Lab Chip 2016, 16, 925-931.

[128] Hung, L.-H., Wang, H.-L., Yang, R.-J., Microfluidics Nanofluidics 2016, 20, 1-9.

[129] Yuan, X., Renaud, L., Audry, M.-C., Kleimann, P., Anal. Chem. 2015, 87, 8695-8701.

[130] Choi, J., Huh, K., Moon, D. J., Lee, H., Son, S. Y., Kim, K., Kim, H. C., Chae, J.-H., Sung, G.

Y., Kim, H.-Y., Hong, J. W., Kim, S. J., RSC Advances 2015, 5, 66178-66184.

[131] Kwak, R., Kang, J. Y., Kim, T. S., Anal. Chem. 2016, 88, 988-996.

[132] Martins, D., Levicky, R., Song, Y.-A., Biosensors Bioelectronics 2015, 72, 87-94.

[133] Martins, D., Wei, X., Levicky, R., Song, Y.-A., Anal. Chem. 2016, 88, 3539-3547.

[134] HyungáShin, I., ChanáKim, H., Lab Chip 2014, 14, 1811-1815.

[135] Kim, B. C., Weerappuli, P., Thouless, M. D., Takayama, S., Lab Chip 2015, 15, 1329-1334.

[136] Lee, Y., Lim, Y., Shin, H., Nanoscale 2016.

[137] Shallan, A. I., Gaudry, A. J., Guijt, R. M., Breadmore, M. C., Chem. Comm. 2013, 49, 28162818.

[138] Shallan, A. I., Guijt, R. M., Breadmore, M. C., Angew. Chem. Int. Ed. Engl. 2015, 54, 7359-

7362.

[139] Jen, C. P., Amstislavskaya, T. G., Kuo, C. C., Chen, Y. H., PLoS One 2014, 9, 8.

[140] Chen, Y.-H., Wu, H. F., Amstislavskaya, T. G., Li, C.-Y., Jen, C.-P., Biomicrofluidics 2016, 10, 024121 .

[141] Cong, Y., Katipamula, S., Geng, T., Prost, S. A., Tang, K., Kelly, R. T., Electrophoresis 2016, 37, 455-462.

[142] Syed, A., Mangano, L., Mao, P., Han, J., Song, Y. A., Lab Chip 2014, 14, 4455-4460.

[143] Tempels, F. W. A., Underberg, W. J. M., Somsen, G. W., de Jong, G. J., Electrophoresis 2008, 29, 108-128.

[144] Ramautar, R., Somsen, G. W., de Jong, G. J., Electrophoresis 2016, 37, 35-44.

[145] Tascon, M., Benavente, F., Sanz-Nebot, V., Gagliardi, L. G., Anal. Chim. Acta 2015, 863, 7885.

[146] Ortiz-Martin, L., Benavente, F., Medina-Casanellas, S., Giménez, E., Sanz-Nebot, V., Electrophoresis 2015, 36, 962-970.

[147] Moreno-González, D., Lara, F. J., Gámiz-Gracia, L., García-Campaña, A. M., J. Chromatogr. A 2014, 1360, 1-8.

[148] Baciu, T., Borrull, F., Calull, M., Aguilar, C., Bioanalysis 2015, 7, 437-447.

[149] Peró-Gascón, R., Pont, L., Benavente, F., Barbosa, J., Sanz-Nebot, V., Electrophoresis 2016, $37,1220-1231$.

[150] Marechal, A., Jarrosson, F., Randon, J., Dugas, V., Demesmay, C., J. Chromatogr. A 2015, 1406, 109-117.

[151] Zhang, Z., Sun, L., Zhu, G., Yan, X., Dovichi, N. J., Talanta 2015, 138, 117-122.

[152] Zhang, Z., Yan, X., Sun, L., Zhu, G., Dovichi, N. J., Anal. Chem. 2015, 87, 4572-4577.

[153] Nordman, N., Barrios-Lopez, B., Lauren, S., Suvanto, P., Kotiaho, T., Franssila, S., Kostiainen, R., Sikanen, T., Electrophoresis 2015, 36, 428-432.

[154] Kumar, S., Sahore, V., Rogers, C. I., Woolley, A. T., Analyst 2016, 141, 1660-1668.

[155] Zhang, X., Zhu, D., Huang, C., Sun, Y., Lee, Y. I., Microchem. J. 2015, 121, 1-5.

[156] Weng, Q., Fu, L., Li, X., An, R., Li, J., Anal. Chim. Acta 2015, 857, 46-52.

This article is protected by copyright. All rights reserved. 
[157] Puig, P., Tempels, F. W. A., Somsen, G. W., de Jong, G. J., Borrull, F., Aguilar, C., Calull, M., Electrophoresis, 2008, 29, 1339-1346.

[158] Tempels, F. W. A., Underberg, W. J. M., Somsen, G. W., de Jong, G. J., Electrophoresis 2007, $28,1319-1326$.

[159] Tempels, F. W. A., Underberg, W. J. M., Somsen, G. W., de Jong, G. J., Anal. Chem. 2004, 76, 4432-4436

[160] Stroink, T., Wiese, G., Teeuwsen, J., Lingeman, H., Waterval, J. C. M., Bult, A., de Jong, G. J., Underberg, W. J. M., Electrophoresis 2003, 24, 897-903.

[161] Stroink, T., Schravendijk, P., Wiese, G., Teeuwsen, J., Lingeman, H., Waterval, J. C. M., Bult, A., de Jong, G. J., Underberg, W. J. M., Electrophoresis 2003, 24, 1126-1134.

[162] Hooker, T. F., Jorgenson, J. W., Anal. Chem. 1997, 69, 4134-4142.

[163] Choi, K., Kim, Y., Chung, D.S., Anal. Chem. 2004, 76, 855-858.

[164] Kim, J., Choi, K., Chung, D. S., Anal. Bioanal. Chem. 2015, 407, 8745-8752.

[165] Springer, V. H., Lista, A. G., Electrophoresis 2015, 36, 1572-1579.

[166] Garcia-Vazquez, A., Borrull, F., Calull, M., Aguilar, C., Electrophoresis 2016, 37, 274-281.

[167] Lee, H. R., Cho, S. M., Kim, J., Chung, D. S., J. Chromatogr. A 2014, 1346, 117-122.

[168] Sung, I. H., Lee, Y. W., Chung, D. S., Anal. Chim. Acta 2014, 838, 45-50.

[169] Pantuckova, P., Kuban, P., Bocek, P., J. Chromatogr. A 2015, 1389, 1-7.

[170] Chen, Y.-L., Huang, Y.-C., Wang, C.-C., Talanta 2015, 143, 27-34.

[171] Furmaniak, P., Kubalczyk, P., Glowacki, R., J. Chromatogr. B 2014, 961, 36-41.

[172] Ge, Y., Guo, Y., Qin, W., Talanta 2014, 121, 50-55.

[173] Jouyban, A., Sorouraddin, M. H., Farajzadeh, M. A., Somi, M. H., Fazeli-Bakhtiyari, R., Talanta 2016, 149, 298-309.

[174] Wang, W.-f., Zhang, H.-g., Qi, S.-d., Chen, H.-1., Chen, X.-g., The Analyst 2015, 140, 42534259.

[175] Xu, X., Liu, L., Jia, Z., Shu, Y., Food Chem. 2015, 176, 219-225.

[176] Kukusamude, C., Srijaranai, S., Kato, M., Quirino, J. P., J. Chromatogr. A 2014, 1351, 110-114.

[177] Tubaon, R. M., Haddad, P. R., Quirino, J. P., J. Chromatogr. A 2014, 1349, 129-134.

[178] Wuethrich, A., Haddad, P. R., Quirino, J. P., Chirality 2014, 26, 734-738.

[179] Wuethrich, A., Haddad, P. R., Quirino, J. P., Electrophoresis 2016, 37, 1139-1142.

[180] Grochocki, W., Markuszewski, M. J., Quirino, J. P., J. Chromatogr. A 2015, 1424, 111-117.

[181] Grochocki, W., Markuszewski, M. J., Quirino, J. P., J. Chromatogr. A 2016, 1442, 140-143.

[182] Wuethrich, A., Haddad, P. R., Quirino, J. P., Electrophoresis 2016, 37, 1122-1128.

[183] Yang, X., Cheng, X., Lin, Y., Tan, Z., Xie, L., Choi, M. M. F., J. Chromatogr. A 2014, 1325, 227-233.

[184] Yang, X., Zhang, S., Wang, J., Wang, C., Wang, Z., Anal. Chim. Acta 2014, 814, 63-68.

[185] Yang, X., Liu, S., Zhang, S., Wang, C., Wang, Z., Anal. Methods. 2014, 6, 6066-6066.

[186] Wuethrich, A., Haddad, P. R., Quirino, J. P., Anal. Chem. 2015, 87, 4117-4123.

[187] Wuethrich, A., Haddad, P. R., Quirino, J. P., Trends Anal. Chem. 2016, 80, 604-611.

[188] Belal, F., El-Din, M. S., Tolba, M., El-Awady, M., Elmansi, H., Microchem. J. 2016, 127, 1121.

[189] Rageh, A. H., Kaltz, A., Pyell, U., Anal. Bioanal. Chem. 2014, 406, 5877-5895.

[190] Xu, X., Jia, Z., Shu, Y., Liu, L., J. Chromatogr. B 2015, 980, 20-27.

This article is protected by copyright. All rights reserved. 
[191] Dziomba, S., Bekasiewicz, A., Prahl, A., Bączek, T., Kowalski, P., Anal. Bioanal. Chem. 2014, 406, 6713-6721.

[192] Hsu, S. H., Hu, C. C., Chiu, T. C., Anal. Bioanal. Chem. 2014, 406, 635-641.

[193] El-Awady, M., Pyell, U., Electrophoresis 2014, 35, 605-616.

[194] Grochocki, W., Markuszewski, M. J., Quirino, J. P., Anal. Methods 2016, 8, 1216-1221.

[195] Dawod, M., Chung, D. S., J. Sep. Sci. 2011, 34, 2790-2799.

[196] Xu, Z. Q., Timerbaev, A. R., Hirokawa, T., J. Chromatogr. A 2009, 1216, 660-670.

[197] Breadmore, M. C., Electrophoresis 2008, 29, 1082-1091.

[198] Breadmore, M. C., Quirino, J. P., Anal. Chem. 2008, 80, 6373-6381.

[199] Dawod, M., Breadmore, M. C., Guijt, R. M., Haddad, P. R., J. Chromatogr. A 2009, 1216,

3380-3386

[200] Meighan, M. M., Dawod, M., Guijt, R. M., Hayes, M. A., Breadmore, M. C., J. Chromatogr. A 2011, 1218, 6750-6755.

[201] Breadmore, M. C., J. Chromatogr. A 2010, 1217, 3900-3906.

[202] Kwon, J. Y., Chang, S. B., Jang, Y. O., Dawod, M., Chung, D. S., J. Sep. Sci. 2013, 36, 19731979.

[203] Wang, W.-f, Ju, F.-r., Ran, Y.-1., Zhang, H.-g., Chen, X.-g., Analyst 2016, 141, 956-962.

[204] Lin, Y.-H., Huang, H.-C., Hsu, W.-L., Anal. Bioanal. Chem. 2015, 407, 7093-7100.

[205] Lu, Y., Wang, D., Kong, C., Jia, C., Breadmore, M. C., Food. Anal. Meth. 2015, 8, 1356-1362.

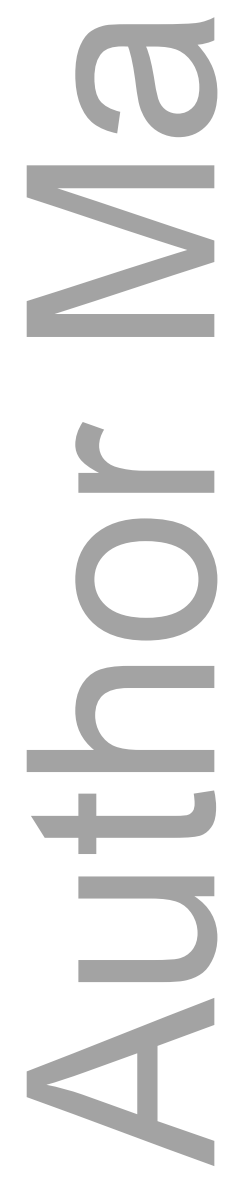

This article is protected by copyright. All rights reserved. 